In cooperation with the U.S. Environmental Protection Agency, National Homeland Security Research Center

\title{
Performance of Traditional and Molecular Methods for Detecting Biological Agents in Drinking Water
}

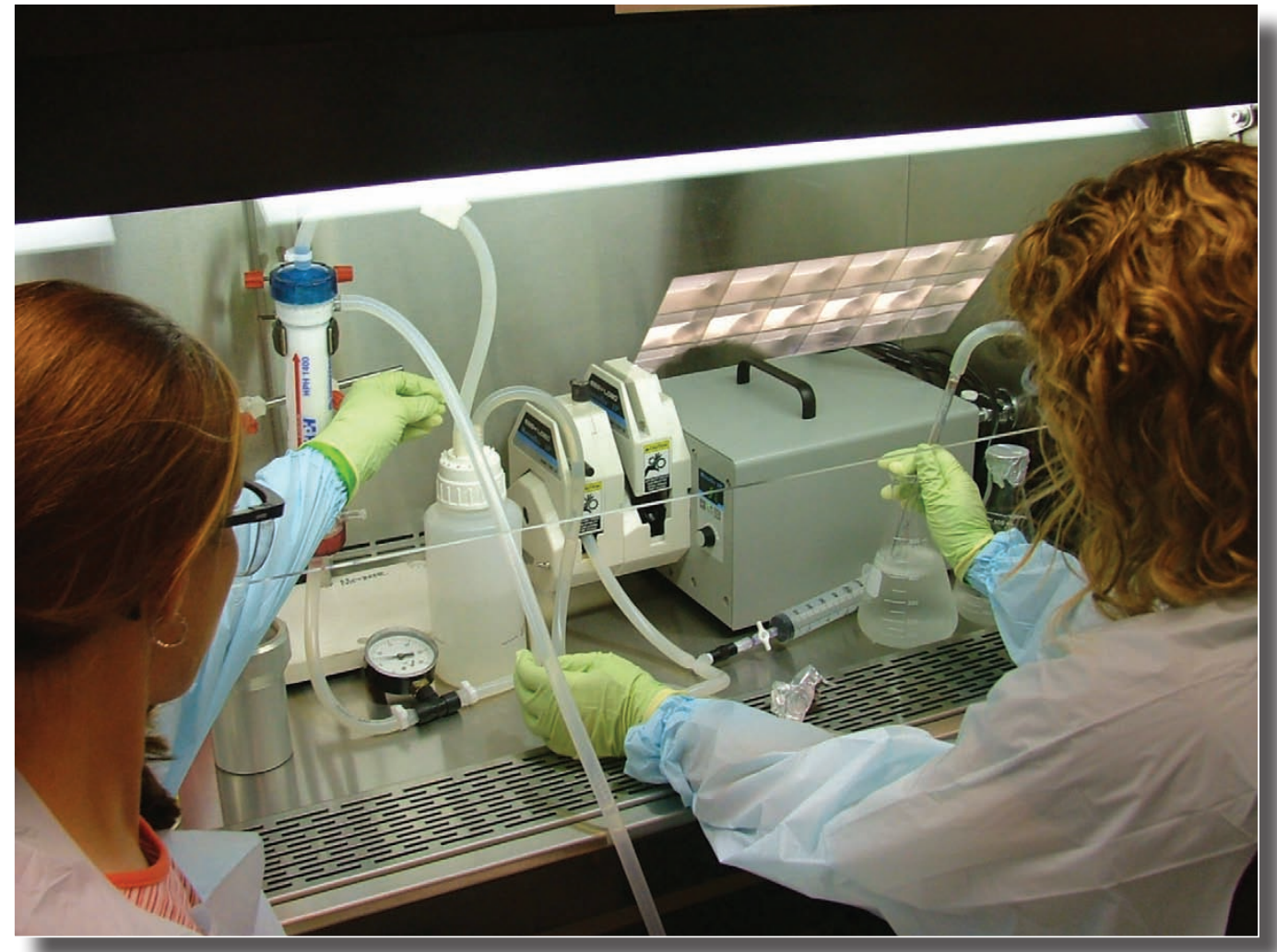

Scientific Investigations Report 2009-5097 
Cover image: View of ultrafiltration being done in a biosafety cabinet at the U.S. Geological Survey's Ohio Water Microbiology Laboratory. (Photograph by Donna Francy, U.S. Geological Survey.) 


\section{Performance of Traditional and Molecular Methods for Detecting Biological Agents in Drinking Water}

By Donna S. Francy, Rebecca N. Bushon, Amie M.G. Brady, Erin E. Bertke, Christopher M. Kephart, Christina A. Likirdopulos, Brian E. Mailot, Frank W. Schaefer, III, and H.D. Alan Lindquist

In cooperation with the U.S. Environmental Protection Agency,

National Homeland Security Research Center

Scientific Investigations Report 2009-5097 


\section{U.S. Department of the Interior \\ KEN SALAZAR, Secretary \\ U.S. Geological Survey \\ Suzette M. Kimball, ActingDirector}

U.S. Geological Survey, Reston, Virginia: 2009

For more information on the USGS - the Federal source for science about the Earth, its natural and living resources, natural hazards, and the environment, visit http://www.usgs.gov or call 1-888-ASK-USGS

For an overview of USGS information products, including maps, imagery, and publications, visit http://www.usgs.gov/pubprod

To order this and other USGS information products, visit http://store.usgs.gov

Any use of trade, product, or firm names is for descriptive purposes only and does not imply endorsement by the U.S. Government.

Although this report is in the public domain, permission must be secured from the individual copyright owners to reproduce any copyrighted materials contained within this report.

Suggested citation:

Francy, D.S., Bushon, R.N., Brady, A.M.G., Bertke, E.E., Kephart, C.M., Likirdopulos, C.A., Mailot, B.E., Schaefer, F.W., III, and Lindquist, H.D.A. 2009, Performance of traditional and molecular methods for detecting biological agents in drinking water: U.S. Geological Survey Scientific Investigations Report 2009-5097, 17 p. 


\section{Contents}

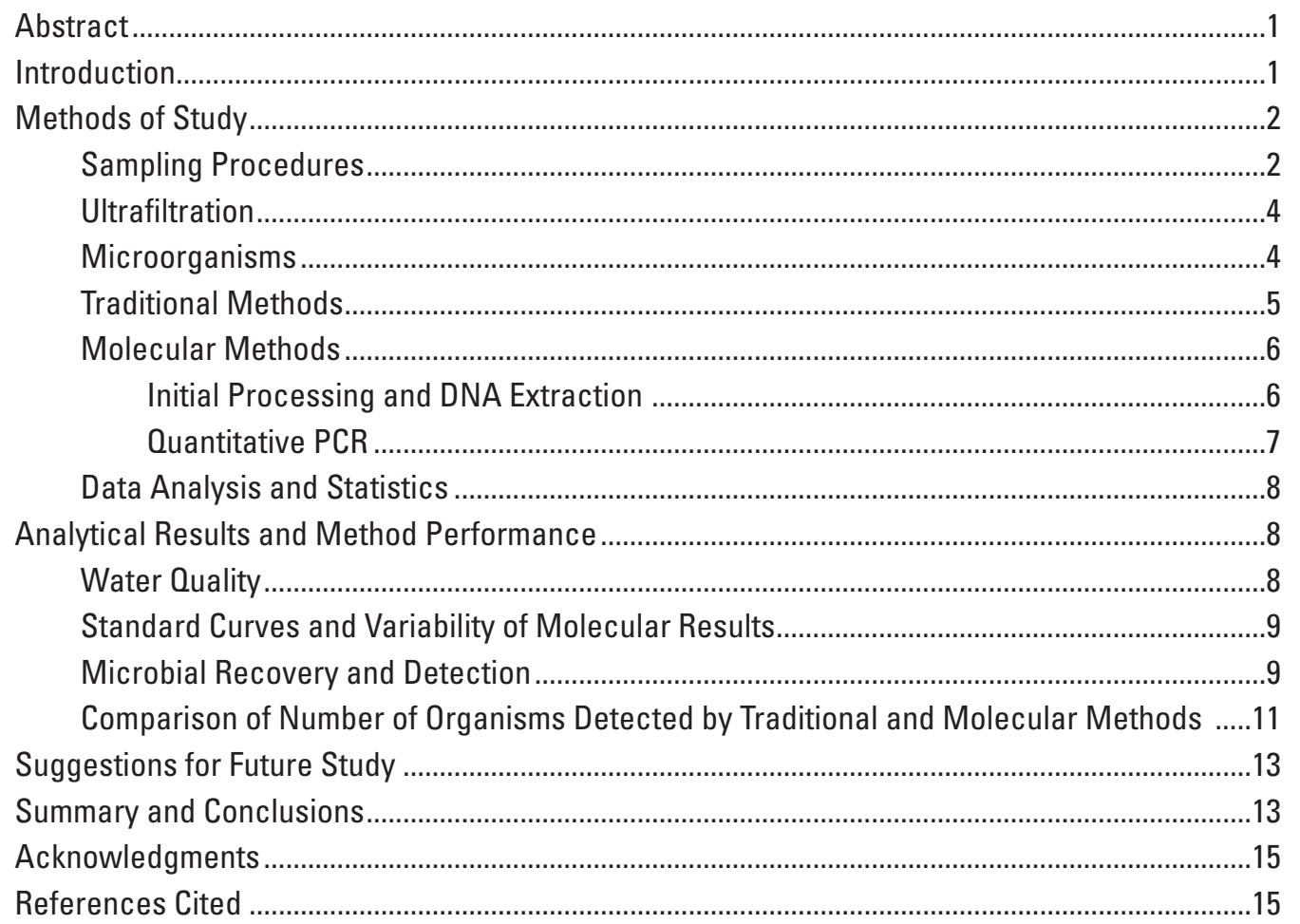

\section{Figures}

1. Standard-curve plot of the cycle-threshold value versus $\log _{10}$-transformed concentrations of Burkholderia cepacia as determined by cultural methods.

2. Graphs showing regression relations for quantiative polymerase chain reaction (qPCR) and culture or immunomagnetic separation/fluoresence antibody (IMS/FA) numbers for seeded retentate samples. 


\section{Tables}

1. Site information and water-quality data for samples collected from Ohio drinking-water treatment plants

2. Primer and probe sequences for biological agents, final concentrations, and targets for each assay.....

3. Performance characteristics of quantitative polymerase chain reaction (qPCR) standard curves for each assay

4. Numbers of colony-forming units for bacteria or oocysts for C. parvum used to seed 100-liter water samples as determined by culture or immunomagnetic separation/fluorescence antibody (IMS/FA) methods

5. Recoveries by culture (for bacteria) or immunomagnetic separation/ fluoresence antibody (IMS/FA) (for C. parvum) methods and detections by quantiative polymerase chain reaction (qPCR) after ultrafiltration of pathogens seeded into 100 -liter water samples

6. Pearson's r correlations between water quality and recoveries of biological agents

\section{Conversion Factors}

\begin{tabular}{lcl}
\hline \multicolumn{1}{c}{ Multiply } & By & \multicolumn{1}{c}{ To obtain } \\
\hline & Length & \\
\hline millimeter $(\mathrm{mm})$ & 0.03937 & inch (in.) \\
micrometer $(\mu \mathrm{m})$ & 0.00003937 & inch (in.) \\
\hline & Area & \\
\hline square meter $\left(\mathrm{m}^{2}\right)$ & 10.76 & square foot $\left(\mathrm{ft}^{2}\right)$ \\
\hline & Volume & gallon $(\mathrm{gal})$ \\
\hline liter $(\mathrm{L})$ & 2.642 & cubic inch $\left(\mathrm{in}^{3}\right)$ \\
\hline milliliter $(\mathrm{mL})$ & 0.06102 & \\
\hline & Mass & ounce, avoirdupois $(\mathrm{oz})$ \\
\hline gram $(\mathrm{g})$ & 0.03527 & foot per second squared $\left(\mathrm{ft} / \mathrm{s}^{2}\right)$ \\
\hline gravitational acceleration $(\boldsymbol{g})$ & Acceleration & \\
\hline
\end{tabular}

Temperature in degrees Celsius $\left({ }^{\circ} \mathrm{C}\right)$ may be converted to degrees Fahrenheit $\left({ }^{\circ} \mathrm{F}\right)$ as follows:

$$
{ }^{\circ} \mathrm{F}=\left(1.8 \times{ }^{\circ} \mathrm{C}\right)+32
$$

Concentrations of total coliforms and Escherichia coli are given in colony-forming units per 100 milliliters (CFU/100 mL).

In addition to milliliters, volumes are given in microliters $(\mu \mathrm{L})$, which are $10^{-6}$ liter $\left(10^{-3}\right.$ milliliter).

Specific conductance is given in microsiemens per centimeter at 25 degrees Celsius $(\mu \mathrm{S} / \mathrm{cm}$ at $\left.25^{\circ} \mathrm{C}\right)$.

Concentrations of chemical constituents in water are given either in milligrams per liter (mg/L) or micrograms per liter ( $\mu \mathrm{g} / \mathrm{L})$. 


\title{
Performance of Traditional and Molecular Methods for Detecting Biological Agents in Drinking Water
}

\author{
By Donna S. Francy, Rebecca N. Bushon, Amie M.G. Brady, Erin E. Bertke, Christopher M. Kephart, Christina \\ A. Likirdopulos, Brian E. Mailot, Frank W. Schaefer, III, and H.D. Alan Lindquist
}

\section{Abstract}

To reduce the impact from a possible bioterrorist attack on drinking-water supplies, analytical methods are needed to rapidly detect the presence of biological agents in water. To this end, 13 drinking-water samples were collected at 9 water-treatment plants in Ohio to assess the performance of a molecular method in comparison to traditional analytical methods that take longer to perform. Two 100-liter samples were collected at each site during each sampling event; one was seeded in the laboratory with six biological agentsBacillus anthracis Sterne (B. anthracis), Burkholderia cepacia (as a surrogate for Bu. pseudomallei), Francisella tularensis Live Vaccine Strain (F. tularensis), Salmonella Typhi (S. Typhi), Vibrio cholerae (V. cholerae), and Cryptospordium parvum (C. parvum). The seeded and unseeded samples were processed by ultrafiltration and analyzed by use of quantiative polymerase chain reaction (qPCR), a molecular method, and culture methods for bacterial agents or the immunomagnetic separation/fluorescent antibody (IMS/FA) method for C. parvum as traditional methods. Six replicate seeded samples were also processed and analyzed.

For traditional methods, recoveries were highly variable between samples and even between some replicate samples, ranging from below detection to greater than 100 percent. Recoveries were significantly related to water $\mathrm{pH}$, specific conductance, and dissolved organic carbon (DOC) for all bacteria combined by culture methods, but none of the water-quality characteristics tested were related to recoveries of C. parvum by IMS/FA. Recoveries were not determined by qPCR because of problems in quantifying organisms by qPCR in the composite seed. Instead, qPCR results were reported as detected, not detected (no qPCR signal), or +/- detected (Cycle Threshold or "Ct" values were greater than 40). Several sample results by qPCR were omitted from the dataset because of possible problems with qPCR reagents, primers, and probes. For the remaining $14 \mathrm{qPCR}$ results (including some replicate samples), F. tularensis and $V$. cholerae were detected in all samples after ultrafiltration, $B$. anthracis was detected in 13 and +/- detected in 1 sample, and $C$. parvum was detected in 9 and +/- detected in 4 samples. Bu. cepacia was detected in nine samples, +/- detected in two samples, and not detected in three samples (for two out of three samples not detected, a different strain was used). The qPCR assay for $V$. cholerae provided two false positive-but late—signals in one unseeded sample. Numbers found by qPCR after ultrafiltration were significantly or nearly significantly related to those found by traditional methods for B. anthracis, F. tularensis, and $V$. cholerae but not for Bu. cepacia and C. parvum. A qPCR assay for $S$. Typhi was not available.

The qPCR method can be used to rapidly detect $B$. anthracis, F. tularensis, and $V$. cholerae with some certainty in drinking-water samples, but additional work would be needed to optimize and test qPCR for Bu. cepacia and C. parvum and establish relations to traditional methods. The specificity for the $V$. cholerae assay needs to be further investigated. Evidence is provided that ultrafiltration and qPCR are promising methods to rapidly detect biological agents in the Nation's drinking-water supplies and thus reduce the impact and consequences from intentional bioterrorist events. To our knowledge, this is the first study to compare the use of traditional and qPCR methods to detect biological agents in large-volume drinking-water samples.

\section{Introduction}

Water supplies in the United States represent potential targets for terrorists wanting to disrupt society or damage important parts of the infrastructure (Meinhardt, 2005). In fact, there have been a number of incidents where disease agents have been spread unintentionally through drinkingwater systems, making intentional contaminantion of biological agents all the more likely (Lindquist and others, 2007). Even if such attacks on water systems do not result in massive casualties, they may result in societal disruptions (Gleick, 2006). A priority concern for those involved with national security is protecting the critical infrastructure against the threat of bioterrorism through contaminated drinking water. It is recognized that early detection and rapid response are the 
keys towards reducing the impact of a biological attack on a drinking-water supply (Meinhardt, 2005). To facilitate early detection, sampling techniques and analytical methods for large volumes of water are needed to quickly detect a variety of potential biological agents.

Ultrafiltration (UF) is a method that can be used to concentrate multiple microorganisms simultaneously (MoralesMorales and others, 2003; Lim and others, 2005). Ultrafiltration uses size exclusion to concentrate microorganisms, where molecules smaller than the filter pore size pass through the membrane and to the effluent line while larger particles (such as microorganisms) are concentrated in the retentate and continue to recirculate within the filter apparatus. Large volumes of water can be filtered in this manner, keeping target organisms in suspension and reducing fouling of the membrane (Holowecky and others, 2009). Ultrafiltration has been shown to be effective in concentrating viruses, bacteria, and protozoan pathogens from large volumes of tap water (Hill and others, 2007; Polaczuk and others, 2008; Holowecky and others, 2009).

After concentrating the target organisms by UF, analytical methods are needed to quickly detect their presence in the retentate. Traditional cultural and microscopic methods are considered the gold standard for isolation, detection, and identification of biological agents (Lim and others, 2005); however, these methods take days before any confirmatory answer is available. Molecular methods, such as quantitative polymerase chain reaction (qPCR), are sensitive and quantitative (Guy and others, 2003) and have the potential for rapid analysis of samples for biological agents from a suspected intentional release. Although it is understood that methods such as qPCR are more rapid and efficient than traditional methods, results from qPCR are still considered presumptive for biological agents. Sample testing must be done in conjunction with traditional cultural methods to provide confirmation of results. According to Roos and Egan (2008), no single method can confirm the presence of a biological threat; multiple tests are required.

Quantitative PCR has been developed and tested for determining levels of protozoan pathogens (Guy 2003; Varma and others, 2003), bacterial indicators (Santo Domingo and others, 2003), and viruses (He and Jiang, 2005) in water matrices, but it has not been extensively tested on large-volume concentrates. In one study of $100-\mathrm{L}$ water samples, investigators found that qPCR could effectively detect viral and bacterial indicators and Cryptosprodium parvum oocysts from UF concentrates but that water quality affected qPCR performance (Hill and others, 2007). Although rapid-detection technologies such as qPCR have been tested for biological agents (Polaczyk and others, 2008), few have been extensively evaluated under field conditions (Lim and others, 2005). More commonly, studies are done to test qPCR methods for biological agents in other settings, such as those for detection of Francisella tularensis in clinical samples (Fulop and others, 1996; Hepburn and others, 2006) or laboratory validation studies of isolates of
Bacillus anthracis (Hoffmaster and others, 2002). Relatively little is known, however, about the ability of qPCR to detect biological agents in large-volume drinking-water samples and the performance of qPCR compared to traditional methods (Francy and others, in press).

The U.S. Geological Survey (USGS), in collaboration with the U.S. Environmental Protection Agency (USEPA), National Homeland Security Research Center, collected 13 raw and finished drinking-water samples to assess the utility and performance of qPCR in comparison to traditional analytical methods for detection of biological agents following UF. Although comparing recoveries of biological agents was an early objective of the study, problems in enumerating organisms in the composite seed precluded achieving this for qPCR; instead, we focused on the variability of recoveries by traditional methods and on detections of organisms by qPCR after UF. Other issues addressed during the study were identifying the best primary isolation medium for each biological agent, determining the effect of water quality on recoveries by traditional methods, and comparing the numbers of organisms detected by qPCR to those detected by traditional methods following UF. To investigate these issues, we targeted six waterborne biological agents: Bacillus anthracis, Burkholderia pseudomallei, Francisella tularensis, Salmonella Typhi, Vibrio cholerae, and Cryptospordium parvum. In addition to qPCR, samples were analyzed by use of traditional culture methods for bacterial agents and by immunomagnetic separation/immunofluorescence microscopy assay (IMS/FA) for $C$. parvum. This report is a companion report to Francy and others (in press) and presents method-performance information not included in the other report.

\section{Methods of Study}

\section{Sampling Procedures}

Raw and (or) finished drinking-water samples were collected from nine water-treatment plants in Ohio to include different types of source waters and water quality (table 1). Five sites were supplied by surface water, and four were supplied by ground water. Some sites were sampled multiple times, either to collect both raw and finished ground water or to confirm results. Finished drinking-water samples were collected from each water-treatment plant after treatment and immediately before distribution. All samples collected from surface-water sources were finished waters; treatment included coagulation, dual-media filtration, lime softening, and freechlorine disinfection. For finished ground-water samples, treatment included flocculation, lime softening, sand filtration, and free chlorine disinfection. Samples were collected from a laboratory or an outside spigot that was swabbed with ethanol, flame-sterilized, and rinsed with sterile deionized water before sampling. 
Table 1. Site information and water-quality data for samples collected from Ohio drinking-water treatment plants.

[Modified from Francy and others (in press). R indicates replicates for two samples collected on the same date; I, II, and III indicate that samples were collected on three sampling dates. Abbreviations: $\mathrm{SW}$ is surface water (all SW samples were finished waters); $\mathrm{GW}$ is groundwater, $\mu \mathrm{S} / \mathrm{cm}, \mathrm{microsiemens}$ per centimeter at 25 degrees Celsius; NTU, nephelometric turbidity units; $\mathrm{mg} / \mathrm{L}$, milligrams per liter; CFU/100 mL, colony-forming units per 100 milliliters]

\begin{tabular}{|c|c|c|c|c|c|c|c|c|c|}
\hline Site & Date sampled & $\begin{array}{l}\text { Water source- } \\
\text { treatment }\end{array}$ & pH & 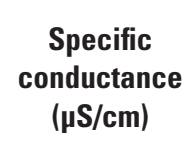 & $\begin{array}{c}\text { Turbidity } \\
\text { (NTU) }\end{array}$ & $\begin{array}{c}\text { Alkalinity } \\
\text { (mg/L as } \\
\mathrm{CaCO}_{3} \text { ) }\end{array}$ & $\begin{array}{c}\text { Hardness } \\
\text { (mg/L as } \\
\mathrm{CaCO}_{3} \text { ) }\end{array}$ & $\begin{array}{c}\text { Dissolved } \\
\text { organic } \\
\text { carbon } \\
\text { (mg/L) }\end{array}$ & $\begin{array}{c}\text { Total } \\
\text { coliforms } \\
\text { (CFU/100 } \\
\mathrm{mL})^{\mathrm{a}}\end{array}$ \\
\hline 1 & $20-F e b-07$ & SW & 7.4 & 658 & 0.6 & 41 & 119 & 1.7 & $<1$ \\
\hline 2 & 12-Mar-07 & GW-raw, R & 7.1 & 754 & 0.3 & 262 & 375 & 1.2 & 8,7 \\
\hline 2 & 05-Nov-07 & GW-finished & 7.6 & 598 & 0.2 & 29 & 122 & 0.9 & $<1$ \\
\hline 3 & 09-Apr-07 & SW I & 9.5 & 249 & 0.1 & 44 & 81 & 1.2 & $<1$ \\
\hline 3 & 10-Dec-07 & SW II, R & 9.4 & 257 & 0.3 & 44 & 91 & 1.8 & $<1$ \\
\hline 3 & $11-F e b-08$ & SW III & 9.7 & 413 & 0.4 & 82 & 109 & 2.2 & $<1$ \\
\hline 4 & 07-May-07 & GW-raw & 7.4 & 614 & 0.2 & 201 & 276 & 0.9 & $<1,1$ \\
\hline 4 & 28-Jan-08 & GW-finished, R & 9.2 & 469 & 0.6 & 67 & 148 & 1.1 & $<1$ \\
\hline 5 & 09-Jul-07 & SW, R & 8.1 & 258 & 0.2 & 29 & 90 & 2.3 & $<1$ \\
\hline 6 & 30-Jul-07 & GW-raw & 6.4 & 435 & 0.5 & 132 & 188 & 0.3 & $<1$ \\
\hline 7 & 20-Aug-07 & SW & 7.4 & 616 & 0.8 & 59 & 179 & 1.9 & $<1$ \\
\hline 8 & 10-Sep-07 & GW-finished, R & 8.7 & 1,321 & 2.1 & 41 & 147 & 0.9 & $<1$ \\
\hline 9 & $15-$ Oct-07 & SW, R & 8.7 & 802 & 0.3 & 26 & 238 & 1.7 & $<1$ \\
\hline
\end{tabular}

${ }^{a}$ Each analysis was done in duplicate. Duplicate analyses that were not the same are reported.

Two 100-L subsamples were collected at each site during each sampling event. One was seeded in the laboratory with six target organisms, and the second was used to determine the natural incidence of target organisms and serve as negative controls (because it is unlikely that unseeded samples will be positive). Subsamples were collected into five 20 -L cubitainer containers. For finished waters, each cubitainer contained sterile sodium thiosulfate solution to achieve a final concentration of $50 \mathrm{mg} / \mathrm{L}$. The samples were stored in a field van when air temperatures were less than $21^{\circ} \mathrm{C}$ and drive time was less than 1 hour; otherwise, they were stored on ice for transport to the laboratory. In the laboratory, samples were stored at $4^{\circ} \mathrm{C}$ and processed within 24 hours of collection. Because of the suspected loss of Burkholderia cepacia (a surrogate for Bu. pseudomallei) at cooler temperatures, samples collected later in the study were kept at room temperature overnight and allowed to reach 17 to $19^{\circ} \mathrm{C}$ before seeding and processing. Field quality-control samples for biological agents included an equipment blank ( $40 \mathrm{~L}$ of autoclaved tap water treated in the same manner as a regular sample) to assess contamination potential and replicate seeded samples at six sites to assess variability.

Specific conductance, temperature, dissolved oxygen, and $\mathrm{pH}$ were measured onsite each time a sample was collected in accordance with standard USGS protocols (Wilde, 2005). Alkalinity was measured using digital titration with sulfuric acid (Hach Model 16900, Hach Company, Loveland, Colo.) (Wilde, 2005, chap. 6.6). Turbidity was measured using a turbidimeter (Hach Model 2100P). Sterile tubing and 1-L sterile bottles containing sodium thiosulfate were used to collect samples for total coliforms and Escherichia coli ( $E$. coli). Samples for total coliforms and E. coli were analyzed by means of the MI agar method (U.S. Environmental Protection Agency, 2002) within 6 hours of sample collection; they were included because they are standard drinking-water-sample analyses. Samples for dissolved organic carbon (DOC), calcium, and magnesium were shipped on ice by overnight mail to the USGS National Water-Quality Laboratory (NWQL) in Denver, Colo. DOC was analyzed by use of ultraviolet-promoted persulfate oxidation and infrared spectrometry (Brenton and Arnett, 1993). Calcium and magnesium concentrations were determined by use of atomic emission spectrometry and inductively coupled plasma (Fishman, 1993); these concentrations were used to calculate hardness (American Public Health Association and others, 1998, Section 2340 B). Quality-control samples for chemical constituents included a field blank (blank water treated in the same manner as a regular sample) and a replicate sample. Quality-control samples for total coliforms and E. coli included a replicate for every sample and two field blanks. For chemical constituents and bacterial indicators, concentrations in replicate samples were in the same range, and concentrations in blanks were below detection (data not shown but are available from the USGS Ohio Water Science Center in Columbus). 


\section{Ultrafiltration}

The 100-L water samples were processed in the laboratory by UF. The UF apparatus is described in detail in Hill and others (2007) and Lindquist and others (2007). The apparatus consisted of a peristaltic pump connected to an ultrafilter and polypropylene retentate bottle (used to contain the sample that was eluted from the filter) with sterilized silicon tubing, tubing connectors, and clamps. The hollow-fiber ultrafilters were single-use Minntech HHP Hemoconcentrators (Minntech Corp., Minneapolis, Minn.) or later in the study, Rexbrane Membrane High-Flux, REXEED-25S (Asahi Kasei Kuraray Medical Co., Ltd., Japan). The Minntech and Ashahi ultrafilters have molecular cutoffs of 65,000- and 29,000-Da, surface areas of $1.31 \mathrm{~m}^{2}$ and $2.5 \mathrm{~m}^{2}$, and fiber inner diameters of 200 $\mu \mathrm{m}$ and $185 \mu \mathrm{m}$, respectively. Side-by-side qualitative comparisons indicated similar recoveries of biological agents by use of either filter (Holowecky and others, 2009). For seeded samples, the inoculum was injected into the sample line through an injection port by using a $60-\mathrm{mL}$ syringe.

Before filtering the sample, filter blocking was done by recirculating $1 \mathrm{~L}$ of 0.1 percent sodium polyphosphate through the UF apparatus. The blocking solution was reduced to 225 $\mathrm{mL}$ in the retentate bottle, the intake tubing was placed into the first 20-L container of sample, and the retentate bottle was filled with sample water. For seeded samples, one-third of the composite seed was injected into the sample line during UF of the second, third, and fourth sample containers. When UF of the $100-\mathrm{L}$ sample was complete (usually after $2-4$ hours), the intake line was closed off and the retentate volume reduced to $225 \mathrm{~mL}$. Forward and backflush rinses were done to elute target organisms from the ultrafilter. For the forward elution, $400 \mathrm{~mL}$ of eluting solution (0.001 percent Tween 80 ) was pumped through the intake line. The $225-\mathrm{mL}$ retentate from the forward rinse was poured into a $250-\mathrm{mL}$ centrifuge tube, previously coated with 2.5 percent bovine serum albumin (BSA) (Sigma-Aldrich Co., St. Louis, Mo.). For the backflush elution, $300 \mathrm{~mL}$ of eluting solution was pumped through the effluent tubing, previously cut by using sterile technique. The $225 \mathrm{~mL}$ backflush retentate was poured into a second $250-\mathrm{mL}$ centrifuge tube. The forward and backflush retentate solutions were centrifuged at $3,300 \mathrm{~g}$ at $4^{\circ} \mathrm{C}$ for $30 \mathrm{~min}$, and the pellets $(15 \mathrm{~mL})$ from both retentates were combined. The final retentate volume was determined for subsequent calculations. After processing each sample, UF equipment was autoclaved or disinfected with 10 percent sodium hypochlorite solution.

\section{Microorganisms}

Six microorganisms were composited and used to seed 100-L water samples (“composite seed”). Bacillus anthracis is the causative agent of anthrax, and although it is typically an airborne contaminant, $B$. anthracis is described as an agent of waterborne disease by Young (1975). For this study, the B. anthracis Sterne ("B. anthracis") strain (Strain 34F2;
Colorado Serum Co., Denver, Colo.), a veterinary vaccine for anthrax, was used. Burkholderia cepacia (ATCC 17616 and 17759) was used as a surrogate for Bu. pseudomallei. Bu. pseudomallei causes meliodosis in humans, a potentially fatal infection endemic in northern Australia and Southeast Asia (Inglis and Sagripanti, 2006). Bu. cepacia is an opportunistic pathogen that is particularly dangerous in cystic fibrosis patients (Henry and others, 1997). Francisella tularensis is the causative agent of the zoonotic disease tularemia, found throughout the northern hemisphere and highly infectious by the aerosol route (Fulop and others, 1996). The F. tularensis Live Vaccine Strain ("F. tularensis," U.S. Centers for Disease Control and Prevention, Atlanta, Ga.) was used in this study. Salmonella enterica serovar Typhi (ATCC 19430) was formerly elevated to species level as S. typhi, but it is now recognized as a serovar and designated as $S$. Typhi. S. Typhi causes typhoid fever, a disease that is common in many parts of the developing world. V. cholerae 01 (ATCC 14035) causes the gastrointestinal disease cholera, and this particular strain was the causative agent of an epidemic in South America during the 1990s. Cryptosporidium parvum is the causative agent of cryptosporidiosis, a wide-spread gastrointenstinal disease that is especially dangerous for persons with compromised immune systems. Cryptosporidium parvum Harley Moon strain (Waterborne Inc., New Orleans, La.) was the only protozoan agent tested during this study.

Fresh spore stocks of $B$. anthracis were prepared using a method that included New Sporulation Medium (NSM), modified from Purdue and others (2003) and described here. A frozen stock of $B$. anthracis was streaked onto three trypticase soy agar plus 5 percent sheep blood (TSA+SB) plates (Becton, Dickinson and Co., Sparks, Md.) and incubated overnight at $35^{\circ} \mathrm{C}$. Eight isolated colonies were suspended in phosphate buffered saline (PBS), and 200- $\mu \mathrm{L}$ aliquots were spread on each of five NSM plates. After 48 hours incubation at $35^{\circ} \mathrm{C}$, a cell suspension was microscopically examined to ensure that at least 90 percent of cells were spores. Biomass from the NSM plates was scraped and washed with deionized water into two 33-mL centrifuge tubes. After two cycles of centrifugation at $12,300 \boldsymbol{g}$ for 10 minutes at $25^{\circ} \mathrm{C}$ and subsequent washes with deionized water, the spore suspensions were composited and stored at $4^{\circ} \mathrm{C}$ for 24 hours to allow lysis of any vegetative cells. To enumerate spores, a $1-\mathrm{mL}$ suspension was heat-treated for 60 minutes at $70^{\circ} \mathrm{C}$ and serially diluted to $10^{-8}$, then $100 \mu \mathrm{L}$ of appropriate dilutions were spread-plated onto TSA+SB plates. Colonies were counted after 24 hours incubation at $35^{\circ} \mathrm{C}$. Aliquots of $1-\mathrm{mL}$ spore stocks were then stored in deionized water at $4^{\circ} \mathrm{C}$ for up to 3 months. Suspensions were checked microscopically before each use to ensure even dispersion and the presence of at least 90 percent spores.

To prepare freezer stocks for non-spore-forming bacteria, cultures of Bu. cepacia, S. Typhi, and V. cholerae were grown overnight and $F$. tularensis for 3 days in tryptic soy broth (TSB). After incubation, cell suspensions were stored at $-70^{\circ} \mathrm{C}$, amended with 30 percent sterile glycerol. To prepare slants, thawed stock cultures were transferred to TSA and 
incubated for the specified times listed above. Fresh slant cultures were reinoculated weekly and the cultures used to seed the water samples did not exceed four generations. Refrigerated slants were transferred to fresh TSA slants for seeding drinking-water samples-overnight cultures for Bu. cepacia, $S$. Typhi, and V. cholerae, and 3-day cultures for F. tularensis.

Viable C. parvum oocysts were flow-counted at the USEPA, Cincinnati, Ohio, using a BD FACSaria (Becton, Dickinson and Co.) flow cytometry system equipped with BD CloneCyt software; the procedures are described in detail elsewhere (Francy and others, 2004). The oocysts were flowcounted to achieve the target number $(10,000$ oocysts for the composite seed and qPCR controls and 100 oocysts for IMS controls) and suspended in $1 \mathrm{~mL}$ of 0.01 percent Tween 20 in $50-\mathrm{mL}$ conical test tubes. The flow-counted tubes were shipped to the USGS by overnight mail and stored at $4{ }^{\circ} \mathrm{C}$ for up to 2 weeks.

The seed inoculum was prepared by adding a 1- $\mu$ loopful of Bu. cepacia, S. Typhi, and V. cholerae and two 1- $\mu \mathrm{L}$ loopfuls of $F$. tularensis into separate 1- $\mathrm{mL}$ aliquots of PBS. Appropriate dilutions of each organism and of a B. anthracis spore suspension were prepared in 1:10 increments in PBS. To prepare the composite seed, $0.9 \mathrm{~mL}$ of the $10^{-4}$ dilution of B. anthracis, Bu. cepacia, S. Typhi, and V. cholerae were added into the tube containing flow-counted $C$. parvum; for $F$. tularensis, $0.9 \mathrm{~mL}$ of the $10^{-3}$ dilution was added. Aliquots of the composite seed were removed before seeding the samples and were enumerated by cultural, IMS/FA, and qPCR methods to obtain pre-UF concentrations.

\section{Traditional Methods}

Primary isolation and confirmation procedures for each target bacterial agent are described below and are based on American Society for Microbiology and others (2001-8) for $B$. anthracis, Bu. pseudomallei (Bu. cepacia), and F. tularensis and American Public Health Association and others (1998, Section 9260) for $S$. Typhi and V. cholerae. Preliminary testing, when needed, was done using Columbus, Ohio, tap water to select the best primary isolation procedure based on recovery of the target organism and utility of the method. For each bacterial agent, dilutions of the composite seed, seeded retentate (aliquot obtained after UF of each seeded water sample), and unseeded retentate (aliquot obtained after UF of each unseeded water sample) were made in order to enumerate each agent using primary isolation procedures. Plates were wrapped in parafilm and incubated for a specified time period. Plates were exposed to air every 24 hours to maintain aerobic conditions. Confirmatory tests of seeded retentates were done by selecting three or four isolates from each primary isolation agar and transferring each isolate to secondary agar-TSA (or TSA+SB for B. anthracis). For unseeded retentates, any suspected target colony was transferred to secondary agar for confirmation. For each media type and confirmatory test, control organisms and blanks were used to ensure proper identification of each target organism and media sterility.
For primary isolation of $B$. anthracis, appropriate dilutions of sample were heat-treated at $70^{\circ} \mathrm{C}$ for 60 minutes, spread-plated onto polymyxin-lysozyme EDTA-thallous acetate (PLET) agar (Hardy Diagnostics, Santa Maria, Calif.) (Knisely, 1966), and incubated at $37^{\circ} \mathrm{C}$. Colonies were enumerated after 2 days of incubation on PLET; B. anthracis colonies were circular cream-white colonies with a groundglass texture. Confirmation tests included the identification of thin, long, Gram+ rods, often appearing in chains, and negative results for $\beta$-hemolysis on PLET and motility on motility test medium (Becton, Dickinson and Co.). Preliminary testing compared PLET with TSA+SB as primary isolation media. Although recoveries were similar by use of PLET and $\mathrm{TSA}+\mathrm{SB}$ (data not shown but are available from the USGS Ohio Water Science Center in Columbus), PLET was used because plates were easier to read than TSA+SB plates. For $\mathrm{TSA}+\mathrm{SB}$, large colonies led to difficulties in discerning individual colonies and obtaining accurate colony counts.

For Bu. cepacia, the selected primary isolation medium was Burkholderia cepacia Selective Agar (BCSA) (Hardy Diagnostics) (Henry and others, 1997), incubated at $35^{\circ} \mathrm{C}$. Because previous research showed that $\mathrm{Bu}$. pseudomallei grew as well on BCSA as on Ashdown's Medium (Peacock and others, 2005), BCSA was selected as the primary isolation media. Colonies were enumerated after 3 days of incubation on BCSA; Bu. cepacia colonies showed variable morphology, from small and dry to moist and large; appearing from purple to purple gray, some with yellow or pink zones in the medium surrounding the colony. Confirmation tests for Bu. cepacia included the identification of short, Gram-rods or coccobacilli; positive tests for catalase, oxidase (may be weak), and motility; a negative test for indole; and resistance to Colistin but with slight susceptibly to Polymyxin B. Confirmatory test results are the same for $\mathrm{Bu}$. pseudomallei, with the notable exception of Bu. psuedomallei being resistant to Polymyxin B.

For F. tularensis, the selected primary isolation medium was Cystine Heart Agar supplemented with hemoglobin, antibiotics, and blood (CHA+B) (Remel, Lenaxa, Kans.), incubated at $35^{\circ} \mathrm{C}$. Francis (1928) originally developed blood dextrose cystine agar, which was later modified by Shaw (1930) and Rhamy (1933) to CHA+B. Colonies were enumerated after 7 days of incubation on $\mathrm{CHA}+\mathrm{B}$; F. tularensis colonies were gray white, 1 to $3 \mathrm{~mm}$ in diameter, round, flat, and smooth, with a characteristic sheen when viewed under indirect light. F. tularensis colonies were large enough to count accurately only after 4-7 days of growth; colonies larger than a pinpoint before 48 hours were not recorded as positive for F. tularensis. During this long incubation time, colonies of Bu. cepacia would sometimes appear on $\mathrm{CHA}+\mathrm{B}$ and mask the growth of slower-growing neighboring $F$. tularensis colonies. Because Bu. cepacia growth preceded F. tularensis growth with the potential to interfere with enumeration of $F$. tularensis, the concentration of F. tularensis in the composite seed was increased. As a result, F. tularensis colonies were sometimes too numerous to count with the usual precision, and calculated concentrations and percent recoveries were 
expressed as estimated values. Confirmation tests for F. tularensis included the identification of tiny, pleomorphic Gramcoccobacilli; a positive test for catalase; and negative tests for oxidase and urease.

For S. Typhi, a five-tube most-probable number (MPN) pre-enrichment $\left(10^{-1}\right.$ to $10^{-5}$ dilutions) was prepared in $9 \mathrm{~mL}$ of buffered peptone water (BPW) (Hardy Diagnostics) and incubated at $37^{\circ} \mathrm{C}$ for 18 to 24 hours. An inoculum from each BPW tube was then transferred to an MPN enrichment tube containing Rappaport-Vasiliadis broth (RV) (Becton, Dickinson, and Co.). After incubation at $43^{\circ} \mathrm{C}$ for 18 to 24 hours, an aliquot from each RV tube was streaked onto part of a BBL CHROMagar plate (Becton, Dickinson, and Co.) and incubated at $35^{\circ} \mathrm{C}$ for 48 hours. Positive $S$. Typhi colonies on BBL CHROMagar were magenta to purple. Confirmation tests for S. Typhi included the identification of Gram- bacilli; a red slant, acid butt, and black precipitate on triple sugar iron agar (TSI) (Becton, Dickinson, and Co.), indicating lactose, sucrose, and dextrose fermentation and $\mathrm{H}_{2} \mathrm{~S}$ production; and VP negative and MR positive on Methyl Red-Vogues-Proskauer Broth (MR/VP), indicating the presence of acetoin and acidity of metabolic end products.

Several other primary isolation agars were tested for $S$. Typhi before selection of BBL CHROMagar. They included bismuth sulfite (BS), Hektoen enteric agar (HE), Miller-Mallinson agar (MM), and Xylose lysine tergitol 4 agar (XLT-4) (BS, HE, and MM are manufactured by Becton, Dickinson and Co.; XLT-4 is manufactured by Hardy Diagnostics). Colonies of $S$. Typhi on BBL CHROMagar, originally developed by Rambach (1990), were bright magenta and easily distinguishable from nontarget colonies. Other mentioned media were excluded from use for the following reasons:

- BS did not recover as many organisms as HE.

- V. cholerae was also able to grow on HE, potentially interfering with enumeration of target colonies.

- MM medium relied on $\mathrm{H}_{2} \mathrm{~S}$ production for identification of target colonies. Some colonies of the positivecontrol organism did not produce $\mathrm{H}_{2} \mathrm{~S}$ on $\mathrm{MM}$ agar, and the $\mathrm{H}_{2} \mathrm{~S}$ indicator (black color within colonies) often faded with extended incubation.

- Growth of the positive-control organism on XLT-4 did not produce enough $\mathrm{H}_{2} \mathrm{~S}$ to distinguish it from nontarget colonies.

For V. cholerae, a five-tube MPN enrichment $\left(10^{-1}\right.$ to $10^{-5}$ dilutions) was prepared in $9 \mathrm{~mL}$ of alkaline peptone water (APW) (Remel) and incubated at $37^{\circ} \mathrm{C}$ for 18 to 24 hours. An aliquot from each APW tube was streaked onto part of a thiosulfate citrate bile salt sucrose agar plate (TCBS) (Remel), incubated at $35^{\circ} \mathrm{C}$ for 72 hours, and enumerated by use of MPN tables. Positive V. cholerae colonies on TCBS were large, smooth, yellow, and slightly flattened, with opaque centers and translucent peripheries. Confirmation tests for V. cholerae included the identification of Gram-straight or curved rods; a yellow slant and butt without a black precipitate on TSI; a positive string test (cells lyse and DNA forms a string in the presence of sodium desoxycholate); a positive oxidase test; and agglutination with Polyvalent $\mathrm{O} 1$ antiserum.

Presumptive colonies of $S$. Typhi and $V$. cholerae in the unseeded retentate of one sample were sent to the USGS National Wildlife Health Center in Madison, Wis., for identification by means of a semiautomated microbial identification system with a 96-well format (Biolog Inc., Hayward, Calif.).

The IMS/FA method for C. parvum was performed as described in USEPA Method 1623 (U.S. Environmental Protection Agency, 2005) with some modifications. Briefly, a Dynabeads anti-Cryptosporidium IMS kit (Invitrogen Corp., Carlsbad, Calif.) was used to separate oocysts from other particulates. A major modification was that the dissociation of the bead oocyst complex was done with heat, not acid, as described in Ware and others (2003). Following IMS, samples were transferred to well slides (Meridian Bioscience Inc., Cincinnati, Ohio) and dried in a desiccating chamber overnight. The slides were stained with a fluorescein-labeled monoclonal antibody, Crypt-a-Glo (Waterborne, Inc.), and counterstained with 4',6-diamidino-2-phenylindole dihydrochloride hydrate (DAPI) (Sigma-Aldrich, D-9542). After the slides were stained, mounting media containing 1,4-diazabiclyclo $(2,2,2)$ octane (Sigma-Aldrich, D-2522) was applied with a cover slip. The slides were microscopically examined within 7 days of staining. For all seeded samples, at least five oocysts were confirmed by DAPI. Positive and negative IMS and stain controls were included with each set of samples, processed and analyzed as described in Francy and others (2004).

\section{Molecular Methods}

\section{Initial Processing and DNA Extraction}

Before analyzing samples by qPCR, initial processing and DNA extraction steps were completed, as described in Francy and others (in press). Briefly, aliquots from the composite seed and the unseeded and seeded retentates were filtered through $0.4-\mu \mathrm{m}$ polycarbonate filters (Whatman Inc., Florham Park, N.J.) and processed using the MO BIO PowerSoil DNA extraction kit (MO BIO Laboratories, Inc., Carlsbad, Calif.). DNA extraction was done using a modified version of the PowerSoil kit, in order to maximize recoveries (Francy and others, in press). The final extraction volume for each sample was $100 \mu \mathrm{L}$. All DNA extracts were stored at $4^{\circ} \mathrm{C}$ until qPCR analysis; all qPCR analyses were done within 24 hours of DNA extraction.

Quality-control samples included DNA extraction blanks, DNA extraction positive controls, and matrix spikes; all were filtered and extracted as described above. DNA extraction blanks contained $10 \mathrm{~mL}$ of PBS. DNA extraction positive controls and matrix spikes both contained positive-control organisms: $100 \mu \mathrm{L}$ of the $10^{-2}$ or $10^{-3}$ dilutions of B. anthracis, Bu. cepacia, F. tularensis, and V. cholerae and 10,000 
flow-counted C. parvum oocysts. For DNA extraction positive controls, positive-control organisms were added to PBS, whereas for matrix spikes, positive-control organisms were added to an aliquot of the unseeded retentate.

\section{Quantitative PCR}

Quantitative PCR reactions were carried out in optical 96-well reaction plates in an Applied Biosystems 7500 RealTime PCR System (Applied Biosystems, Foster City, Calif.). Assays were optimized by Edgewood Chemical Biological Center (ECBC) (Francy and others, in press). Reaction mixtures contained $12.5 \mu \mathrm{L}$ of the $2 \mathrm{X}$ TaqMan Universal PCR Master Mix (Applied Biosystems), $5 \mu \mathrm{L}$ of DNA extract template, 0.3 or $0.4 \mu \mathrm{L}$ of the primers and probes in order to achieve the concentrations listed in table 2, and moleculargrade water. Thermal cycling conditions were as follows: 2 minutes at $50^{\circ} \mathrm{C}, 10$ minutes at $95^{\circ} \mathrm{C}$, and 45 cycles of 5 seconds at $95^{\circ} \mathrm{C}$ and 31 seconds at $60^{\circ} \mathrm{C}$.

Primers and probes were selected for a variety of targets (table 2). A qPCR assay for $S$. Typhi was not available during the sampling period. One qPCR assay was used for $C$. parvum, and two qPCR assays were used for the other four bacterial agents. For B. anthracis, Bu. cepacia, and V. cholerae, one

Table 2. Primer and probe sequences for biological agents, final concentrations, and targets for each assay.

[ Table modified from Francy and others (in press). Assays in italics and bold were expected to be positive for the laboratory-seeded strain. Assays developed by Dr. Sanjiv Shah, Edgewood Chemical Biological Center, Aberdeen Proving Ground, Md. $\mu$ M, micromolar. ]

\begin{tabular}{|c|c|c|c|c|c|}
\hline Organism & Primer or probe & Sequence & $\begin{array}{c}\text { Concen- } \\
\text { tration } \\
(\mu \mathrm{M})\end{array}$ & Target & $\begin{array}{c}\text { GenBank } \\
\text { Accession } \\
\text { Number }\end{array}$ \\
\hline \multirow{4}{*}{ B. anthracis } & BA1 reverse primer & TCGGTTCGTTAAATCCAAATGC & 0.3 & \multirow{2}{*}{$\begin{array}{l}\text { Protective antigen } \\
\text { gene (pagA) }\end{array}$} & \multirow{2}{*}{ AF268967 } \\
\hline & BA1 probe & ACGACTAAACCGGATATGACATTAAAAGAAGCCCTTAA & 0.3 & & \\
\hline & BA2 forward primer & TGCGCGAATGATATATTGGTTT & 0.3 & \multirow{2}{*}{$\begin{array}{l}\text { Capsular antigen gene } \\
\text { (сарB) }\end{array}$} & \multirow[t]{2}{*}{ M24150 } \\
\hline & $\mathrm{BA} 2$ probe & TGACGAGGAGCAACCGATTAAGCGC & 0.3 & & \\
\hline \multirow[t]{3}{*}{ Ви. серасіа* } & BC1 forward primer & TCGACGCAGAACCTGAACAA & 0.3 & \multirow{3}{*}{$\begin{array}{l}\text { Motor rotation gene } \\
\quad(\operatorname{mot} \mathrm{B})\end{array}$} & \multirow[t]{3}{*}{ AY536437 } \\
\hline & BC1 reverse primer & GACTTGCGGTTCAGCACGAT & 0.3 & & \\
\hline & BC1 probe & CGGACCCGCTCGATCCGGAG & 0.3 & & \\
\hline \multirow{3}{*}{$\begin{array}{l}\text { Cryptosporidium } \\
\text { spp. }\end{array}$} & CP1 forward primer & GATCACTATTACTAACGATAAGGGTAGATTATCA & 0.4 & \multirow{3}{*}{$\begin{array}{l}70 \mathrm{kDa} \text { Heat shock } \\
\text { protein gene } \\
(\text { hsp } 70)\end{array}$} & \multirow[t]{3}{*}{ AB104730 } \\
\hline & CP1 reverse primer & TGCTCATCCTCACCCTTGTATTT & 0.4 & & \\
\hline & CP1 probe & AGGACGATATTGAACGTATGGTTAATGATGCTGA & 0.3 & & \\
\hline \multirow[t]{5}{*}{ F. tularensis } & FT1 forward primer & AACAATGGCACCTAGTAATATTTCTGG & 0.3 & \multirow{3}{*}{$\begin{array}{l}\text { Outer membrane pro- } \\
\text { tein gene (fopA) }\end{array}$} & \multirow[t]{3}{*}{ AF097542 } \\
\hline & FT1 reverse primer & CCACCAAAGAACCATGTTAAACC & 0.3 & & \\
\hline & FT1 probe & TGGCAGAGCGGGTACTAACATGATTGGT & 0.3 & & \\
\hline & FT2 forward primer & ATTACAATGGCAGGCTCCAGA & 0.3 & \multirow{2}{*}{$\begin{array}{l}17 \mathrm{kDa} \text { Protein gene } \\
\quad(\text { tul4) }\end{array}$} & \multirow[t]{2}{*}{ AY219239 } \\
\hline & FT2 reverse primer & GCCCAAGTTTTATCGTTCTTCTCA & 0.3 & & \\
\hline \multirow{2}{*}{ Vibrio spp. } & VC2 reverse primer & CGATAACCGAGTTGATCATTCAGA & 0.4 & \multirow{2}{*}{$\begin{array}{l}\text { V. cholerae hemolysin } \\
\text { gene (hlyA) }\end{array}$} & \multirow{2}{*}{ M36855 } \\
\hline & VC2 probe & TGACAGCACGGGAGCCGGC & 0.4 & & \\
\hline
\end{tabular}

* Primers and probes were designed for $\mathrm{Bu}$. pseudomallei but were shown to react with $\mathrm{Bu}$. cepacia. 
assay was expected to be positive for the laboratory-seeded organism, and the second assay was expected to be negative because it targeted an agent-specific virulence-factor gene. For F. tularensis, both assays were expected to be positive with the laboratory-seeded strain.

Quality-control samples for qPCR are described in Francy and others (in press). Quality-control samples included DNA extraction blanks (10 $\mathrm{ml}$ of PBS), DNA extraction positive controls (positive-control organisms added to duplicate aliquots of PBS), matrix spikes (positive-control organisms added to duplicate aliquots of unseeded retentates), qPCR positive controls, and no template controls (NTCs). The DNA extraction blanks, qPCR positive controls, and no template controls (NTCs) were run as single reactions. For qPCR positive controls, DNA extracts from each organism's standard curve (known to produce detectable levels of fluorescence) were used as DNA templates. For NTCs, molecular-grade reagent water was used instead of DNA template. All samples were run by qPCR in triplicate.

Standard curves were developed for each assay before and during the sample-collection and analysis period (Francy and others, in press). Briefly, six dilutions of each organism were prepared and extracted separately and by two different analysts in order to fully characterize the variability in the extraction step. For C. parvum, each dilution used to prepare the standard curve was flow-counted separately by the USEPA. Concentrations of each organism were determined by cultural or microscopic methods as described above.

\section{Data Analysis and Statistics}

For S. Typhi and V. cholerae, MPN results were computed as described in American Public Health Association and others (1998, Part 9221 C). For culture or IMS/FA methods, numbers of organisms in composite seeds and seeded retentates were adjusted per volume analyzed. For cultural or IMS/ FA results, if an organism was not found in the seeded retentate, the lower detection limit was used. The lower detection limit was calculated by assuming that one organism was found in the undilute seeded retentate, and this value was used to calculate a less-than number. Recoveries of bacterial organisms by culture methods or C. parvum oocysts by IMS/FA were calculated by dividing the number of each microbe in the seeded retentate (including less-than values) by the number in the composite seed and multiplying by 100 .

The numbers of organisms found by qPCR in seeded retentate samples were determined from standard curves and then adjusted per volume analyzed. Cycle threshold (Ct) values from the standard curves were plotted against $\log _{10}$ concentrations for each assay. Regression analysis was done, and the resulting equation was used to interpolate unknown sample results for each biological agent. Ct values less than 40 were considered detections of the target organism in this study. $\mathrm{Ct}$ values greater than 40 were qualified as detected with the possibility of a false-positive result. Recoveries of organisms by qPCR were not calculated because of the uncertainty of $\mathrm{Ct}$ values greater than 40 and problems with quantifying organisms by qPCR in the composite seed.

In addition, the 95-percent confidence interval for each standard curve regression (SAS, Inc., Cary, N.C.) was used to provide a measurement of the level of uncertainty associated with predicting concentrations from qPCR results. Matrixspike and positive-control samples were used during processing of samples to determine matrix inhibition and DNA extraction efficiency. These data points were plotted on the standard curve to demonstrate consistent performance of each assay during each qPCR run. Specifically, this was determined by identifying whether the data points were within the 95-percent confidence interval for the standard-curve regression.

Pearson's correlation coefficients were used to describe the strength of the association between recoveries of organisms by culture or IMS/FA and water-quality characteristics. Linear regression analysis was used to predict numbers of organisms found by traditional methods from numbers found by qPCR.

\section{Analytical Results and Method Performance}

\section{Water Quality}

Thirteen drinking-water samples were collected from nine water-treatment plants from February 2007 to February 2008 (table 1). For surface-water sources, one sample was collected from each of four sites, and three samples were collected from one site (site 3). For ground-water sources, one sample was collected from each of two sites (raw or finished), and two samples were collected from each of another two sites (raw and finished). During repeat sampling at site 3, although $\mathrm{pH}$ was consistently high, specific conductance, alkalinity, hardness, and DOC were higher in the third sample than in the other two samples. In repeat samplings at the two groundwater sites (sites 2 and 4), water-quality characteristics were different because raw or finished water was collected.

Wide ranges of water-quality values were found among sites. The $\mathrm{pH}$ ranged from 6.4 at site 6 (raw ground water) to 9.7 at site 3 (surface water). Specific conductance ranged from $249 \mu \mathrm{S} / \mathrm{cm}$ at site 3 to $1,321 \mu \mathrm{S} / \mathrm{cm}$ at site 8 (finished ground water). Water from site 8 also had the highest turbidity -2.1 NTU. Alkalinities were low to moderate, except for $262 \mathrm{mg} / \mathrm{L}$ at site 2 and $201 \mathrm{mg} / \mathrm{L}$ at site 4 (both were raw ground water). Hardness ranged from $81 \mathrm{mg} / \mathrm{L}$ at site 3 (surface water) to 375 $\mathrm{mg} / \mathrm{L}$ at site 2 (raw ground water). Dissolved organic carbon concentrations were all below $2.0 \mathrm{mg} / \mathrm{L}$, except at site 5 and one sample at site 3 (both surface water). Total coliforms were found at sites 2 and 4 (both raw ground water) in concentrations ranging from 1 to $8 \mathrm{CFU} / 100 \mathrm{~mL}$; all samples were negative for $E$. coli. 


\section{Standard Curves and Variability of Molecular Results}

Table 3 shows performance characteristics for each standard curve for the assays expected to be positive by using laboratory-seed strains. The dynamic range of the standard curve is the lowest and highest concentrations of the standards that were used in the regression analysis. Variability in the DNA extraction step was included in standard-curve development by diluting the organisms and extracting each dilution, rather than extracting one concentration and then diluting that one extraction. As seen in an example standard curve for $B u$. cepacia (fig. 1), variability around each concentration could be high ( $\pm 4 \mathrm{Ct}$ ), based on the 95 -percent confidence intervals. For example, a Ct of 30 would give a predicted Bu. cepacia concentration of 132,000 with upper and lower confidence limits of 1,030,000 and 16,800, respectively. On the basis of data from standard curves, $\mathrm{Ct}$ values less than 40 were considered detections of target organisms in this study, Ct values $>40$ were considered +/- detections, and results with no qPCR signal were considered nondetections.

\section{Microbial Recovery and Detection}

Different levels of biological agents were present in the composite seed for inoculation into 100-L water samples (table 4). The highest median seed values were for $F$. tularensis and $V$. cholerae. Wide ranges of composite seed numbers were used for all organisms except for $C$. parvum oocysts, which were prepared by flow cytometry. Recoveries for culture or IMS/FA methods for organisms seeded into drinking-water samples are listed in table 5 . Recoveries were highly variable between samples and, in a few cases, were even variable between replicate pairs of the same sample (replicate pairs are shaded in table 5). Correlation analysis of the data summarized in table 4 indicated that seed level did not have an effect on recovery for any pathogen except for $S$. Typhi (data not shown but are available from the USGS Ohio Water Science Center in Columbus). For $S$. Typhi, as seed concentration increased, recovery decreased $(\mathrm{r}=-0.505, p=0.0388)$.

The qPCR data are presented in table 5 as detected (+), not detected (-), or detected with a $\mathrm{Ct}>40(+/-)$ in the seeded retentate. As expected, the laboratory-seed strains were always negative by qPCR for assays $B$. anthracis 2 , Bu. cepacia 1 , and $V$. cholerae 2; these results are not included in table 5 . Recoveries by qPCR were not calculated because, for several samples, organisms were detected in the seeded retentate (after UF) but not detected in the composite seed (before UF). It was therefore concluded that the quantification of organisms in the composite seed by qPCR was unreliable. There were other problems with the qPCR method. There were many nondetections or $+/$ - detections by qPCR in samples $3,4,10$, and 11 . For samples 3 and 4, results from seeded samples and positive-control samples were unexpectedly low or not detected.
Table 3. Performance characteristics of quantitative polymerase chain reaction (qPCR) standard curves for each assay.

[Table from Francy and others (in press)]

\begin{tabular}{lcccc}
\hline \multicolumn{1}{c}{ Assay } & Slope & $\begin{array}{c}\text { y-inter- } \\
\text { cept }\end{array}$ & $\mathbf{R}^{2}$ & Dynamic range \\
\hline B. anthracis 1 & -4.39 & 50.9 & 0.913 & $1,200-1,200,000$ \\
Bu. cepacia 2 & -4.86 & 54.9 & 0.901 & $910-9,100,000$ \\
C. parvum 1 & -3.12 & 47.9 & 0.876 & $1,000-100,000$ \\
F. tularensis 1 & -3.97 & 51.0 & 0.880 & $660-66,000,000$ \\
F. tularensis 2 & -4.09 & 53.7 & 0.830 & $660-66,000,000$ \\
V. cholerae 1 & -4.63 & 49.8 & 0.941 & $130-13,000,000$ \\
\hline
\end{tabular}

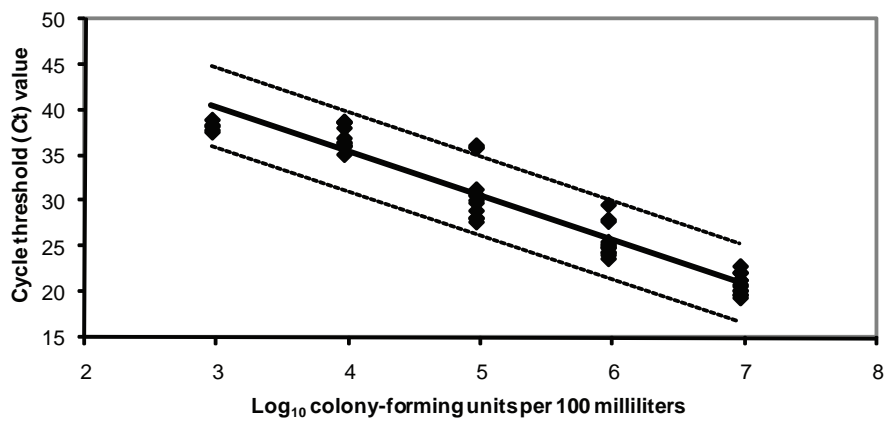

Figure 1. Standard-curve plot of the cycle-threshold value versus $\log _{10}$-transformed concentrations of Burkholderia cepacia as determined by cultural methods.

Table 4. Numbers of colony-forming units for bacteria or oocysts for C. parvum used to seed 100-liter water samples as determined by culture or immunomagnetic separation/ fluorescence antibody (IMS/FA) methods.

\begin{tabular}{lrrr}
\multicolumn{1}{c}{ Organism } & Minimum & Maximum & Median \\
& & & \\
\hline B. anthracis & 367 & 30,400 & 11,800 \\
Bu. cepacia & $<33$ & 49,100 & 10,350 \\
C. parvum & 2,310 & 5,570 & 3,840 \\
F. tularensis & 8,250 & $1,040,000$ & 197,000 \\
S. Typhi & 12,100 & 264,000 & 86,900 \\
V. cholerae & 869 & 594,000 & 187,000 \\
\hline
\end{tabular}


Table 5. Recoveries by culture (for bacteria) or immunomagnetic separation/fluoresence antibody (IMS/FA) (for C. parvum) methods and detections by quantiative polymerase chain reaction (qPCR) after ultrafiltration of pathogens seeded into 100-liter water samples.

[Table modified from Francy and others (in press). R, replicate sample (shading denotes field replicates); +, detected; -, not detected; +/-, detected, but Ct value was greater than 40 ; $<$, not detected at less than this value; ND, not determined.]

\begin{tabular}{|c|c|c|c|c|c|c|c|c|c|c|c|c|c|}
\hline \multirow{3}{*}{$\begin{array}{l}\text { Sam- } \\
\text { ple \# }\end{array}$} & \multirow{3}{*}{ Site } & \multicolumn{12}{|c|}{ Recoveries by culture or IMS/FA (percent) and detections by qPCR } \\
\hline & & \multicolumn{2}{|c|}{ B. anthracis } & \multicolumn{2}{|c|}{ Bu. cepacia } & \multicolumn{2}{|c|}{ C. parvum } & \multicolumn{3}{|c|}{ F. tularensis } & \multirow{2}{*}{$\begin{array}{c}S . \\
\text { Typhi } \\
\text { Cul- } \\
\text { ture }\end{array}$} & \multicolumn{2}{|c|}{ V. cholerae } \\
\hline & & $\begin{array}{l}\text { Cul- } \\
\text { ture }\end{array}$ & $\begin{array}{c}\text { qPCR } \\
1\end{array}$ & $\begin{array}{l}\text { Cul- } \\
\text { ture }\end{array}$ & $\begin{array}{c}\text { qPCR } \\
2\end{array}$ & $\begin{array}{l}\text { Cul- } \\
\text { ture }\end{array}$ & qPCR & $\begin{array}{l}\text { Cul- } \\
\text { ture }\end{array}$ & $\begin{array}{c}\text { qPCR } \\
1\end{array}$ & $\begin{array}{c}\text { qPCR } \\
2\end{array}$ & & $\begin{array}{l}\text { Cul- } \\
\text { ture }\end{array}$ & $\begin{array}{c}\text { qPCR } \\
1\end{array}$ \\
\hline 1 & 1 & 87.3 & + & 10.2 & + & 46.5 & $+/-$ & 6.3 & + & + & 68.6 & 37.2 & + \\
\hline 2 & 2 & 16.7 & + & 29.6 & $+/-$ & 10.5 & $+/-$ & 5.4 & + & + & 396 & 55.2 & + \\
\hline $2 \mathrm{R}$ & 2 & 30.0 & + & 12.3 & + & 74.1 & $+/-$ & 8.6 & + & + & 96.1 & 88.7 & + \\
\hline 3 & 3 & 21.4 & $\mathrm{ND}^{\mathrm{b}}$ & 22.4 & $\mathrm{ND}^{\mathrm{b}}$ & $<2.2$ & $\mathrm{ND}^{\mathrm{b}}$ & 1.0 & $\mathrm{ND}^{\mathrm{b}}$ & $\mathrm{ND}^{\mathrm{b}}$ & 78.2 & 77.8 & $\mathrm{ND}^{\mathrm{b}}$ \\
\hline 4 & 4 & 4.1 & $\mathrm{ND}^{\mathrm{b}}$ & $1.8^{\mathrm{a}}$ & $\mathrm{ND}^{\mathrm{b}}$ & 14.0 & $\mathrm{ND}^{\mathrm{b}}$ & 0.34 & $\mathrm{ND}^{\mathrm{b}}$ & $\mathrm{ND}^{\mathrm{b}}$ & 4.6 & 12.8 & $\mathrm{ND}^{\mathrm{b}}$ \\
\hline 5 & 5 & 40.0 & + & $<22.4^{\mathrm{a}}$ & + & 105 & + & 20.2 & + & + & 145 & 4.5 & + \\
\hline $5 R$ & 5 & 54.1 & + & $<28.6^{\mathrm{a}}$ & + & 84.2 & + & 21.7 & + & + & 122 & 8.0 & + \\
\hline 6 & 6 & 20.8 & + & $<1.0^{\mathrm{a}}$ & $+/-$ & $\mathrm{ND}^{\mathrm{b}}$ & + & 0.20 & + & + & 4.1 & 11.6 & + \\
\hline 7 & 7 & 28.4 & + & $5.4^{\mathrm{a}}$ & + & 87.6 & $+/-$ & 13.0 & + & + & 25.1 & 25.1 & + \\
\hline 8 & 8 & 7.0 & + & $5.3^{\mathrm{a}}$ & + & 74.2 & + & 17.3 & + & + & 16.7 & 145 & + \\
\hline $8 \mathrm{R}$ & 8 & 19.3 & + & $<0.5^{\mathrm{a}}$ & + & 25.5 & + & 20.4 & + & + & 371 & 11.9 & + \\
\hline 9 & 9 & 13.7 & + & $<0.4^{\mathrm{a}}$ & $-c$ & 40.5 & + & 13.9 & + & + & $\mathrm{ND}^{\mathrm{b}}$ & $\mathrm{ND}^{\mathrm{b}}$ & + \\
\hline $9 \mathrm{R}$ & 9 & 19.5 & + & $<0.3^{\mathrm{a}}$ & $-c$ & 52.2 & + & 26.4 & + & + & $\mathrm{ND}^{\mathrm{b}}$ & $\mathrm{ND}^{\mathrm{b}}$ & + \\
\hline 10 & 2 & 12.1 & $\mathrm{ND}^{\mathrm{b}}$ & $<240^{\mathrm{a}}$ & $\mathrm{ND}^{\mathrm{b}}$ & 244 & $\mathrm{ND}^{\mathrm{b}}$ & 19.4 & $\mathrm{ND}^{\mathrm{b}}$ & $\mathrm{ND}^{\mathrm{b}}$ & 71.7 & 11.0 & $\mathrm{ND}^{\mathrm{b}}$ \\
\hline 11 & 3 & 49.3 & $\mathrm{ND}^{\mathrm{b}}$ & 52.5 & $\mathrm{ND}^{\mathrm{b}}$ & 71.5 & $\mathrm{ND}^{\mathrm{b}}$ & 23.1 & $\mathrm{ND}^{\mathrm{b}}$ & $\mathrm{ND}^{\mathrm{b}}$ & 118 & 288 & $\mathrm{ND}^{\mathrm{b}}$ \\
\hline $11 \mathrm{R}$ & 3 & 34.8 & $\mathrm{ND}^{\mathrm{b}}$ & 27.4 & $\mathrm{ND}^{\mathrm{b}}$ & 77.3 & $\mathrm{ND}^{\mathrm{b}}$ & 33.0 & $\mathrm{ND}^{\mathrm{b}}$ & $\mathrm{ND}^{\mathrm{b}}$ & 48.5 & 106 & $\mathrm{ND}^{\mathrm{b}}$ \\
\hline 12 & 4 & 82.6 & + & 13.3 & + & 74.3 & + & 14.3 & + & + & 45.7 & 79.7 & + \\
\hline $12 \mathrm{R}$ & 4 & 39.0 & $+/-$ & 22.3 & - & 92.2 & $+/-$ & 40.4 & + & + & 129 & 39.3 & + \\
\hline 13 & 3 & 43.7 & + & 28.9 & + & 103 & + & 30.1 & + & + & 204 & 288 & + \\
\hline
\end{tabular}

${ }^{a}$ Results were removed from subsequent data analysis because of possible temperature effects on culture.

${ }^{\mathrm{b}}$ Not determined because results did not meet quality-assurance requirements.

${ }^{\mathrm{c}}$ A different strain was used.

Samples 3 and 4 were reextracted and run by qPCR, and similar results were obtained. It was hypothesized that primer and probe reagents had begun to degrade; therefore, new reagents were purchased, and subsequent sample and quality-control results were as expected. Samples 10 and 11 were processed by using a DNA extraction kit lot number that was later shown to be inefficient in extracting the DNA and was the cause of nondetections by qPCR. In separate tests, statistically significant differences in qPCR results for three qPCR assays ( $B$. anthracis, F. tularensis, and V. cholerae) were found by using different reagent lot numbers of the DNA extraction kit (data not shown but are available from the USGS Ohio Water Science Center in Columbus).

Recoveries of B. anthracis ranged from 4.1 to 87.3 percent for the culture method. Recoveries for replicate pairs were generally in the same range except for the 39 to 82.6 percent replicate pair for sample 12. Suspect Bacillus colonies were found on PLET (primary isolation medium) from one unseeded retentate sample (sample 11); the organism was later confirmed as nontarget growth and was not B. anthracis (the colony had atypical morphology on secondary agar and was motile). The qPCR method detected $B$. anthracis in all 14 samples with results, providing a + /- detection in only 1 sample.

Recoveries of Bu. cepacia for the culture method ranged from less than detection to 52.5 percent and were generally in the same range for replicate pairs. A large number of recoveries, however, were below detection for the culture method. $B u$. cepacia recoveries in samples 1-3 were moderate (10.2 to 29.6 percent) but decreased to very low percentages in samples 4-6 ( $<1.0$ to 1.8 percent). For sample 7, a new culture stock was ordered from the supplier. Recoveries increased somewhat but were still low for sample 7 (5.4 percent) and sample 8 ( 5.3 and $<0.5$ percent). For sample 9 , in an attempt 
to obtain better growth of $\mathrm{Bu}$. cepacia, a different strain was ordered from the supplier (ATCC 17759). The new strain was reported to be motile and isolated from forest soil; the original strain was nonmotile but was also isolated from soil. The new strain was not detected by either culture or qPCR methods in sample 9. Returning to the original $\mathrm{Bu}$. cepacia strain for sample 10, organisms were still not recovered by culture. For sample 11, water samples were kept overnight at room temperature and allowed to reach $17^{\circ} \mathrm{C}$ before seeding. (Samples were previously kept in the refrigerator overnight). For sample 11, Bu. cepacia recoveries by the culture method were 52.5 and 27.4 percent in replicates A and B, respectively. Samples 12 and 13 were treated the same as sample 11 , and recoveries were comparable. Out of 14 samples with results by qPCR, 9 were positive, 2 were + - - detected, and 3 were negative (two of these negatives resulted from using a difference strain of $\mathrm{Bu}$ cepacia). In sample 12, Bu. cepacia was detected by qPCR in one replicate but not in the other replicate; for the nondetection by qPCR, the organism was detected by culture. In four samples, Bu. cepacia was detected by qPCR but was below detection for the culture method because of possible temperature effects described above.

Recoveries for $C$. parvum ranged from below detection to 244 percent for IMS/FA. Recoveries for replicate pairs for IMS/FA were different in samples 2 and 8. For the IMS step alone, recoveries were less variable, ranging from 23 to 87 percent with an average recovery of 65.4 percent (data not shown but are available from the USGS Ohio Water Science Center in Columbus). Of the 14 samples with results for $C$. parvum by qPCR, 9 were positive and 5 were $+/$ - detected. For the samples with +/- detections, $C$. parvum was detected by IMS/FA.

Recoveries for $F$. tularensis ranged from 0.2 to 40.4 percent for the culture method. Recoveries for replicate pairs for the culture method were generally in the same range, except for sample 12. F. tularensis was detected in all 14 samples by both qPCR assays.

Recoveries for $S$. Typhi ranged from 4.1 to 396 percent for the culture method; samples were not analyzed for $S$. Typhi by qPCR. Recoveries for replicate pairs were highly variable; this was because cell counts were made using MPN estimates and not from direct plating methods. In sample 2, typical $S$. Typhi colonies were found on BBL CHROMagar (primary isolation medium) from the unseeded retentate; these colonies were later confirmed as nontarget growth and identified as Pseudomonas maculicola.

Recoveries for $V$. cholerae ranged from 4.5 to 288 percent for the culture method. As with $S$. Typhi culture results, cell counts were made using MPN estimates, and recoveries for replicate pairs were highly variable. $V$. cholerae was detected by qPCR in all 14 samples. It is important to note, however, that the $V$. cholerae qPCR assay resulted in a late but positive signal for the unspiked retentate of sample $2(\mathrm{Ct}=36.71)$. Positive signals for $V$. cholerae in all samples ranged from $\mathrm{Ct}=28.53$ to $\mathrm{Ct}=37.89$, with an average of $\mathrm{Ct}=31.11$ (data not shown but available from the USGS Ohio Water Science
Center in Columbus). In sample 2, suspect colonies on TCBS (primary isolation medium) in the unseeded retentate were later identified as non-Vibrio and members of the families Enterobacteriaceae or Pseudomanaceae. The qPCR assay for $V$. cholerae on pure cultures of the nontarget isolate from TCBS and the nontarget isolate on BBL CHROMagar (mentioned in the previous paragraph on $S$. Typhi) resulted in a late signal for the TCBS isolate $(\mathrm{Ct}=39.31)$ and a $>40 \mathrm{Ct}$ for the BBL CHROMagar isolate.

The relations between sample water-quality characteristics and associated recoveries are listed in table 6 as a median recovery of all bacteria combined, for individual bacterial pathogens, and for C. parvum. The C. parvum data are presented separately because analysis was done by IMS/ FA. For all bacterial data combined, significant (relations were considered significant if $\mathrm{p} \leq 0.1$ ) positive correlations were found between median recoveries by culture methods and $\mathrm{pH}$ or DOC, and a significant negative correlation was found between recoveries and specific conductance. For Bu. cepacia, none of the relations were significant because of a small dataset. The relations between water-quality characteristics and $S$. Typhi recoveries did not follow a pattern similar to those of the other bacterial pathogens (that is, the correlation was positive for $S$. Typhi when it was negative for other organisms). No significant relations were found between IMS/FA recoveries and any water-quality characteristic measured.

\section{Comparison of Number of Organisms Detected by Traditional and Molecular Methods}

The data representing the linear-regression relations between qPCR and culture or IMS/FA numbers in seeded retentates are shown for each organism in figure 2 . The slope of the regression line is a measure of the rate of change in culture or IMS/FA numbers with change in qPCR numbers. The slopes were positive and significant (at $p \leq 0.05$ ) for $B$. anthracis and $F$. tularensis and were nearly significant for V. cholerae ( $p=0.1018$ ). Among these three organisms, the slope was highest for $V$. cholerae. For Bu. cepacia, although the coefficient of determination of the regression was moderate $\left(R^{2}=0.39\right)$, the slope was not significant because of the small dataset. The relations between IMS/FA and qPCR results for C. parvum were not significant, and the regression line was essentially flat. For F. tularensis, the relation was stronger $\left(R^{2}\right.$ values were higher and slopes were more significant) between culture results and qPCR assay 1 than qPCR assay 2 . More insight can be gained by examining the placement of 1:1 lines as compared to linear regression lines. For B. anthracis and to a lesser extent, for $B$ u. cepacia, the regression line was near the 1:1 line. For $F$. tularensis, both assay regressions were strongly influenced by one data point and qPCR numbers were biased high over culture numbers. In contrast, for $V$. cholerae, culture numbers were considerably higher than qPCR numbers. 
Table 6. Pearson's r correlations between water quality and recoveries of biological agents.

[Relations that were significant at $\mathrm{p}<0.05$ are in italics and bold: those at $\mathrm{p}>0.05$ and $<0.1$ are in bold only]

\begin{tabular}{lccccccc}
\hline & $\begin{array}{c}\text { All bacteria } \\
\text { combined }\end{array}$ & B. anthracis & Bu. cepacia & F. tularensis & $\begin{array}{c}\text { S. } \\
\text { Typhi }\end{array}$ & V. cholerae & C. parvum \\
\hline Number & $19 *$ & 19 & 9 & 19 & 17 & 17 & 18 \\
pH & $\mathbf{0 . 4 9 8}$ & 0.192 & 0.415 & $\mathbf{0 . 6 3 0}$ & 0.086 & $\mathbf{0 . 5 9 3}$ & -0.059 \\
Specific conductance & $\mathbf{- 0 . 4 3 8}$ & $\mathbf{- 0 . 4 0 8}$ & -0.521 & -0.109 & 0.294 & -0.131 & -0.184 \\
Turbidity & -0.163 & -0.142 & -0.385 & 0.105 & 0.189 & 0.001 & -0.113 \\
Alkalinity & -0.168 & -0.241 & -0.164 & $-\mathbf{0 . 4 7 9}$ & 0.214 & -0.067 & -0.306 \\
Hardness & -0.346 & $-\mathbf{0 . 3 9 4}$ & -0.243 & $\mathbf{- 0 . 4 1 1}$ & 0.240 & -0.190 & -0.326 \\
Dissolved organic carbon & $\mathbf{0 . 5 4 8}$ & $\mathbf{0 . 4 0 0}$ & 0.425 & $\mathbf{0 . 4 2 1}$ & 0.097 & 0.291 & 0.087 \\
\hline
\end{tabular}

* Median values for recoveries of all bacteria combined for each sample.

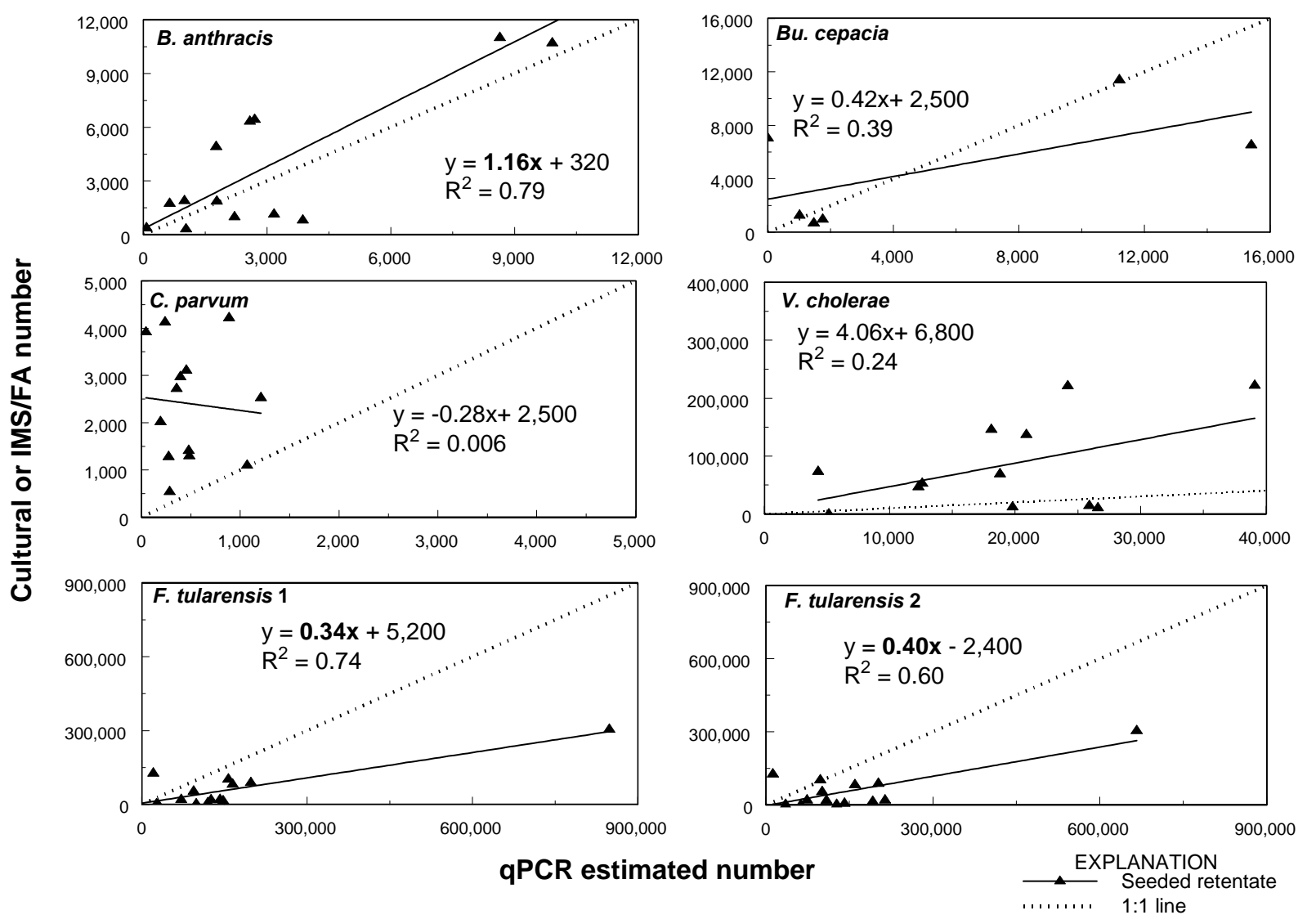

Figure 2. Regression relations for quantiative polymerase chain reaction (qPCR) and culture or immunomagnetic separation/fluoresence antibody (IMS/FA) numbers for seeded retentate samples. Slopes in bold were statistically significant at alpha $=0.05$. (Figure modified from Francy and others, in press.) 


\section{Suggestions for Future Study}

- Effects from physical and chemical components of water matrices on recoveries by qPCR could be further investigated. Because qPCR recoveries could not be reliably calculated in this study, the effects of water quality on qPCR recoveries could not be determined. It is well known, however, that water matrices may contain organic and inorganic substances with the potential to inhibit PCR (Wilson, 1997). These include humic and phenolic compounds, both contributors to DOC.

- The specificity for the V. cholerae qPCR assay needs to be further investigated. Suspect target colonies, later confirmed as nontarget growth, were found in one of the unseeded retentate samples for $S$. Typhi and $V$. cholerae. The $V$. cholerae qPCR assay provided late, but positive results for these isolates. The assay, which targets the 23S rRNA gene, is, therefore, not 100 percent specific for $V$. cholerae.

- More testing would need to be done to determine the ability of the primers and probes to detect different strains of Bu. cepacia. A second strain was not detected by the qPCR assay in this study.

- Additional work would be needed to increase qPCR detection rates for some of the target organisms. The qPCR method can be used to rapidly detect $B$. anthracis, F. tularensis, and V. cholerae with some certainty in drinking-water samples; however, additional work would be needed to optimize and test qPCR for $\mathrm{Bu}$. cepacia and C. parvum.

- For all organisms, additional research would be needed to reduce the variability of qPCR, including reducing variability of the DNA extraction procedure, and to determine minimum detection limits for $q P C R$ assays.

- A geographically widespread study is needed, especially in areas where $\mathrm{F}$. tularensis and Bu. cepacia may be found in unseeded samples.

\section{Summary and Conclusions}

Water supplies in the United States are potential targets for bioterrorists wanting to disrupt society or damage important parts of the infrastructure. To reduce the impact and consequences from an intentional contamination event with biological agents, methods are needed to rapidly detect the presence of these agents in drinking-water supplies. Ultrafiltration (UF) is a method that can be used to concentrate multiple microorganisms simultaneously from drinking water; however, after concentration, analytical methods are still needed to quickly detect their presence in the retentate. Because traditional cultural and microscopic methods take days before any confirmatory answer is available, molecular methods, such as quantitative polymerase chain reaction (qPCR), are considered a viable alternative. Minimal work has been done, however, to test qPCR for detecting biological agents in targeted testing of water samples and comparing results to that of traditional analytical methods.

Thirteen drinking-water samples were collected from nine water-treatment plants in Ohio to assess performance of qPCR in comparison to traditional analytical methods for detection of biological agents. Two 100-L subsamples were collected at each site during each sampling event. One was seeded in the laboratory with six target organisms-Bacillus anthracis Sterne ("B. anthracis"), Burkholderia cepacia (as a surrogate for Bu. pseudomallei), Francisella tularensis Live Vaccine Strain ("F. tularensis”), Salmonella Typhi, Vibrio cholerae, and Cryptospordium parvum. Six replicate seeded samples were included to determine processing and analytical variability. The seeded and unseeded samples were processed by UF within 2 to 4 hours and analyzed by qPCR and by traditional culture methods for bacterial agents and by immunomagnetic separation/immunofluorescence microscopy assay (IMS/FA) for C. parvum. Specific conductance, temperature, dissolved oxygen, $\mathrm{pH}$, turbidity, and alkalinity were measured and samples were collected and analyzed for dissolved organic carbon (DOC), calcium, and magnesium concentrations. Total coliform and E. coli concentrations were determined by use of a standard membrane-filtration method.

Because the focus of the study was a comparison of methods, considerable time and effort was expended to identify and document the best methods and modifications needed for each target organism. For example, PLET agar was found to be superior to TSA+SB agar for primary isolation of B. anthracis, and BBL CHROMagar was selected over other agar methods for primary isolation of $S$. Typhi. The IMS/ FA method was used for C. parvum, with heat dissociation substituted for acid dissociation. DNA extraction steps were modified to optimize recoveries. The manufacturer's protocol for the DNA extraction kit, which calls for the removal of a portion of the total volume during wash steps, was modified such that the entire volume was removed. Subsequent volume additions were adjusted accordingly.

Recoveries were calculated for culture or IMS/FA methods for different levels of organisms. Recoveries were highly variable between samples and were sometimes even variable between replicate pairs of the same sample. Recoveries ranged from 4.1 to 87.3 percent for $B$. anthracis, $<0.3$ to 52.5 percent for Bu. cepacia, <2.2 to 244 percent for C. parvum, 0.2 to 40.4 percent for F. tularensis, 4.1 to 396 percent for $S$. Typhi, and 4.5 to 288 percent for $V$. cholera. The most consistent recoveries among samples and for replicate pairs were obtained for $F$. tularensis. Wide ranges of recoveries were found for $S$. Typhi and $V$. cholera, even among replicate pairs; this was because cell counts were made by using MPN estimates. Recoveries of C. parvum by IMS/FA were also highly variable among 
the different sites. This was not unexpected, because other researchers found a wide range of recoveries in stream and source waters (Francy and others, 2004; Kuhn and Oshima, 2002; U.S. Environmental Protection Agency, 2001). Recoveries of bacterial agents by culture methods can be affected by loss of culturability, as shown by reduced recoveries of Burkholderia suspected to be caused by lower temperatures in this study. Although there are no available data for Bu. cepacia, it was reported that storing Bu. pseudomallei (the bacterial agent for which $B$. cepacia is serving as a surrogate) in a refrigerator converts a proportion of the bacteria to a nonculturable state (Inglis and Sagripanti, 2006). Further, investigators found that survival of $B u$. pseudomallei was extended at temperatures of 24 and $32^{\circ} \mathrm{C}$ but not at lower temperatures. Indeed, the distribution of meliodosis, the disease caused by Bu. pseudomallei, is primarily limited to tropical and semitropical locations between latitudes $20^{\circ} \mathrm{N}$ and $20^{\circ} \mathrm{S}$ (Inglis and Sagripanti, 2006).

The drinking-water samples included wide ranges of $\mathrm{pH}$, specific conductance, alkalinity, and hardness, with narrower ranges of turbidity and DOC. Recoveries by the culture method for all bacteria combined were significantly related to $\mathrm{pH}, \mathrm{DOC}$ (positive correlations), and specific conductance (negative correlation). Although these relations were not investigated further, it seems likely that $\mathrm{pH}, \mathrm{DOC}$, and specific conductance may affect the physiological state of the organisms and their potential to grow in culture. Recoveries by IMS/FA for C. parvum were not related to any water-quality characteristic. This is contrary to other reports in the literature where investigators found that the water matrix could affect recovery of C. parvum by use of IMS/FA; specifically, that recoveries were related to turbidity (Kuhn and Oshima, 2002; Francy and others, 2004) and pH (Kuhn and others, 2002).

Recoveries by qPCR were not determined because in many of the qPCR results, there was a stronger signal in the seeded retentate than in the composite seed. This is contrary to conventional thinking because more organisms were recovered after UF than were seeded into the system. Possible explanations for enhanced detection after UF include poor extraction efficiency in the composite seed and (or) removal or dilution of inhibitors from the water sample during UF. Possible inhibitors to qPCR in the composite seed may have come from the $C$. parvum tube used to prepare the composite seed $(0.01$ percent Tween) or from carryover from the agar media used to grow bacterial pathogens. Because of these limitations, organisms could not be accurately quantified by qPCR in the composite seed. In addition, the qPCR method is limited by the bias and variability inherent in many nucleic acid techniques (Lim and others, 2005). These include variability of DNA-extraction efficiencies. In this study, an inefficient DNA extraction kit lot resulted in removal of the qPCR results (most were nondetections) of samples 10 and 11 from the dataset. The suspected degradation of primers and probes led to a large proportion of nondetection by qPCR for samples 3 and 4 , and they also were removed from the dataset.

The qPCR results were reported as detected, not detected, or $+/$ - detected (Ct values $>40$ ) in the seeded retentates. These are the samples that went through the UF procedure, so it is important from a practical standpoint to be able to detect these organisms in seeded retentates. Not including results from samples 3, 4, 10, and 11, F. tularensis and V. cholerae were positively detected in all 14 samples. B. anthracis was detected in the seeded retentates of every sample except that it was only +/- detected in one of two replicates of sample 12 . Detections of Bu. cepacia and C. parvum by qPCR in seeded retentates were more inconsistent. In sample 9, Вu. серасіа was not detected, but a different strain was used. More testing would need to be done to determine the ability of the primers and probes to detect different strains of Bu. cepacia. It is important to note, however, that Bu. cepacia was positively detected by qPCR in 9 of 14 samples and was sometimes detected by qPCR and not by culture. Among the organisms tested, C. parvum qPCR results had the greatest number in which Ct was $>40$. C. parvum is present in an environmentally resistant form, the resilience of which may affect DNA-extraction efficiency. In addition, C. parvum was seeded in relatively low numbers, which may help to explain the large number of +/- detections by qPCR. Recoveries could not be reliably calculated in this study, so the effects of water quality on qPCR recoveries were not determined.

The potential for false positive results also could be further investigated. Suspect target colonies, later confirmed as nontarget growth, were found in one of the unseeded retentate samples for $S$. Typhi and $V$. cholerae (sample 2) and one of the unseeded retentate samples for $B$. anthracis (sample 11). Because the $V$. cholerae qPCR assay provided a late, but positive result in sample 2, this assay, which targets the 23S rRNA gene, is not 100 percent specific for $V$. cholerae. The nontarget, suspect growth on PLET in sample 11 suggested that PLET is not 100 percent specific for B. anthracis. In a study by Papaparaskevas and others (2004), investigators found that PLET was selective for $B$. anthracis by inhibiting two thirds of contaminating bacilli as well as other bacteria, but the specificity of PLET was low. The qPCR results for $B$. anthracis for sample 11 were not available.

If qPCR were to be used to rapidly detect biological agents in drinking-water samples, it would be important to establish the relations between qPCR and traditional methods. Therefore, regression equations were developed to determine whether numbers from culture or IMS/FA methods could be predicted from numbers from qPCR in filtered water samples (seeded retentates). The slopes of the regression lines were significant for B. anthracis and both F. tularensis assays and nearly significant for $V$. cholerae. Although a positive slope was found for these relations for Bu. cepacia, the sample size was too small to be significant. For $C$. parvum; negative slopes and a low $R^{2}$ indicated that, even with additional testing, it may not be possible to define a significant relation. For B. anthracis and Bu. cepacia, cultural numbers were similar to qPCR numbers. For V. cholerae, cultural numbers were about 10 times the qPCR numbers. For F. tularensis, the opposite was true; qPCR numbers were about twice the cultural numbers. F. tularensis 
cells may have been injured during UF and may have become nonculturable, but they were still detected by qPCR.

In conclusion, this is the first known study to compare the use of traditional and qPCR methods to detect biological agents in large-volume drinking-water samples (Francy and others, in press). This study confirmed that the UF procedure can simultaneously concentrate bacterial and protozoan pathogens from a variety of $100-\mathrm{L}$ drinking-water samples. Most important, if qPCR is used as a presumptive test for biological agents in drinking water, it is important to determine whether there are false negative results related to traditional methods. In this regard, only three samples were false negatives (all for Bu. cepacia); and even in several samples, Bu. cepacia was detected by qPCR but not by culture. The qPCR method can be used to rapidly enumerate $B$. anthracis, F. tularensis, and $V$. cholerae with some certainty in drinking-water samples; levels found by the qPCR method were significantly related to levels found by the culture methods for these organisms after UF. However, the specificity for the $V$. cholerae assay needs to be further investigated. Although Bu. cepacia and C. parvum were detected by qPCR in the majority of samples analyzed, additional work would be needed to optimize and test qPCR for these organisms to reduce nondetections or $+/$ - detections and establish relations to numbers by traditional methods. For all organisms, additional research would be needed to reduce the variability of qPCR, including reducing variability of the DNA extraction procedure. Minimum detection limits for qPCR and the influence of drinking-water quality on qPCR could also be investigated in future studies. A geographically widespread study would be needed, especially in areas where F. tularensis and $\mathrm{Bu}$. cepacia may be found in unseeded samples.

\section{Acknowledgments}

We thank the water purveyors for providing access to their water-treatment plants, David Blehert (USGS National Wildlife Health Center, Madison, Wis.) for identifying nontarget isolates, Mark Wolcott (U.S. Army Medical Research Institute of Infectious Diseases, Ft. Detrick, Md., USA) for providing expertise and a protocol on Bacillus spore preparation, and Sanjiv Shah (U.S. Environmental Protection Agency) for information on the qPCR primers and probes.

\section{References Cited}

American Public Health Association, American Water Works Association, and Water Pollution Control Federation, 1998, Standard methods for the analysis of water and wastewater (20th ed.): Washington, D.C., American Public Health Association [variously paginated].
American Society for Microbiology, Centers for Disease Control and Prevention, and Association of Public Health Laboratories, 2001-8, Sentinel level clinical microbiology laboratory guidelines: Washington, D.C., accessed March 18, 2009, at http://www.asm.org/policy/index.asp?bid=6342

Brenton, R.W., and Arnett, T.L., 1993, Methods of analysis by the U.S. Geological Survey National Water Quality Laboratory-Determination of dissolved organic carbon by UVpromoted persulfate oxidation and infrared spectrometry: U.S. Geological Survey Open-File Report 92-480, p. 12.

Fishman, M.J., ed., 1993, Methods of Analysis by the USGS National Water Quality Laboratory-Determination of inorganic and organic constituents in water and fluvial sediments: U.S. Geological Survey Open-File Report 93-125, p. 101-112.

Francis, E., 1928, Symptoms, diagnosis and pathology of tularemia: Journal of the American Medical Association, v. 91, p. 1155-1160.

Francy, D.S., Simmons O.D., III, Ware, M.W., Granger, E.J., Sobsey, M.D., and Schaefer F.W., III, 2004, Effects of seeding procedures and water quality on recovery of Cryptosporidium oocysts from stream water by using U.S. Environmental Protection Agency Method 1623: Applied and Environmental Microbiology, v. 70, p. 4118-4128.

Francy, D.S., Bushon, R.N., Brady, A.M.G., Bertke, E.E., Kephart, C.M., Likirdopulos, C.A., Mailot, B.E., Schaefer, F.W. III, and Lindquist, H.D. Alan, in press, Comparison of traditional and molecular analytical methods for detecting biological agents in raw and drinking water following ultrafiltration: Journal of Applied Microbiology.

Fulop, M., Leslie, D., and Titball, R., 1996, A rapid, highly sensitive method for the detection of Francisella tularensis in clinical samples using the polymerase chain reaction: American Journal of Tropical Medicine \& Hygiene, v. 54, p. 364-366.

Gleick, P.H., 2006, Water and terrorism: Water Policy, v. 8, p. 481-503.

Guy, R.A., Payment, P., Krull, U.J., and Horgen, P.A., 2003, Real-time PCR for quantification of Giardia and Cryptosporidium in environmental water samples and sewage: Applied and Environmental Microbiology, v. 69, p. $5178-5185$.

He, J-W., and Jiang, S., 2005, Quantification of enterococci and human adenoviruses in environmental samples by realtime PCR: Applied and Environmental Microbiology, v. 71, p. 2250-2255. 
Henry, D.A., Campbell, M.E., LiPuma, J.J., and Speert, D.P., 1997, Identification of Burkholderia cepacia isolates from patients with cystic fibrosis and use of a simple new selective medium: Journal of Clinical Microbiology, v. 35, p. 614-619.

Hepburn, M.J., Purcell, B.K., Lawler, J.V., Coyne, S.R., Petitt, P.L., Sellers, K.D., Norwood, D.A., and Ulrich, M.P., 2006, Live vaccine strain Francisella tularensis is detectable at the inoculation site but not in blood after vaccination against tularemia: Clinical Infectious Diseases, v. 43, p. 711-716.

Hill, V.R., Kahler, A.M., Jothikumar, N., Johnson, T.B., Hahn, D., and Cromeans, T.L., 2007, Multistate evaluation of an ultrafiltration-based procedure for simultaneous recovery of enteric microbes in 100-liter tap water samples: Applied and Environmental Microbiology, v. 73, p. 4218-4225.

Hoffmaster, A.R., Meyer, R.F., Bowen, M.P., Marston, C.K., Weyant, R.S., Barnett, G.A., Sejvar, J.J., Jernigan, J.A., Perkins, B.A., and Popovic, T., 2002, Evaluation and validation of a real-time polymerase chain reaction assay for rapid identification of Bacillus anthracis: Emerging Infectious Diseases, v. 8, p. 1178-1181.

Holowecky, P.M., James, R.R., Lorch, D.P., Straka, S.E. and Lindquist, H.D.A., 2009, Evaluation of ultrafiltration cartridges for a water sampling apparatus: Journal of Applied Microbiology, v. 106, no. 3, p. 738-747.

Inglis, T.J.J., and Sagripanti, J.-L., 2006, Environmental factors that affect the survival and persistence of Burkholderia pseudomallei: Applied Environmental Microbiology, v. 72, p. 6865-6875.

Knisely, R.F., 1966, Selective medium for Bacillus anthracis: Journal of Bacteriology, v. 92, p. 784-786.

Kuhn, R.C., and Oshima, K.H., 2002, Hollow-fiber ultrafiltration of Cryptospoiridium parvum oocysts from a wide variety of 10-L surface water samples: Canadian Journal of Microbiology, v. 48, p. 542-549.

Kuhn, R.C., Rock, C.M., and Oshima, K.H., 2002, Effects of $\mathrm{pH}$ and magnetic material on immunomagnetic separation of Cryptosporidium oocysts from concentrated water samples: Applied and Environmental Microbiology, v. 68, p. 2066-2070.

Lim, D.V., Simpson, J.M., Kearns, E.A., and Kramer, M.F., 2005, Current and developing technologies for monitoring agents of bioterrorism and biowarfare: Clinical Microbiological Reviews, v. 18, p. 583-607.
Lindquist, H.D.A., Harris, S., Lucas, S., Hartzel, M., Riner, D., Rochele, P., and DeLeon, R., 2007, Using ultrafiltration to concentrate and detect Bacillus anthracis, Bacillus atrophaeus subspecies globigii, and Cryptosporidium parvum in 100-liter water samples: Journal of Microbiological Methods, v. 70, p. 484-492.

Meinhardt, P.L., 2005, Water and bioterrorism-Preparing for the potential threat to U.S. water supplies and public health: Annual Review of Public Health, v. 26, p. 213-237.

Morales-Morales, H.A., Vidal, G., Olszewski, J., Rock, C.M., Dasgupta, D., Oshima, K.H., and Smith, G.B., 2003, Optimization of a reusable hollow-fiber ultrafilter for simultaneous concentration of enteric bacteria, protozoa, and viruses from water: Applied and Environmental Microbiology, v. 69 , p. 4098-4012.

Papaparaskevas, J., Houhoula, D.P., Papadimitriou, M., Saroglou, G., Legakis, N.J., and Zerva, L., 2004, Ruling out Bacillus anthracis: Emerging Infectious Diseases, v. 10, p. $732-735$.

Peacock, S.J., Chieng, G., Cheng, A.C., Dance, D.A.B., Amornchai, P., Wongsuvan, G., Teerawattanasook, N., Chierakul, W., Day, N.P.J., and Wuthiekanun, V., 2005, Comparison of Ashdown's medium, Burkholderia cepacia medium, and Burkholderia pseudomallei selective agar for clinical isolation of Burkholderia pseudomallei: Journal of Clinical Microbiology, v. 43, p. 5359-5361.

Polaczyk, A.L., Narayanan, J., Cromeans, T.L., Hahn, D., Roberts, J.M., Amburgey, J.E., and Hill, V.R., 2008, Ultrafiltration-based techniques for rapid and simultaneous concentration of multiple microbe classes from 100-L tap water samples: Journal of Microbiological Methods, v. 73, p. 92-99.

Purdue, M.L., Karns, J., Higgins, J., and Van Kessel, J.A., 2003, Detection and fate of Bacillus anthracis (Sterne) vegetative cells and spores added to bulk tank milk: Journal of Food Protection, v. 66, p. 2349-2354.

Rambach, A., 1990, New plate medium for facilitated differentiation of Salmonella spp. from Proteus spp. and other enteric bacteria: Applied and Environmental Microbiology, v. 56, p. 301-303.

Rhamy, B.W., 1933, A new and simplified medium for Pasteurella tularensis and other delicate organisms: American Journal of Clinical Pathology, v. 3, p. 121-124.

Roos, J.W., and Egan, C., 2008, Laboratory resources, in Emanuel, P., Roos, J.W., and Hiyogi, K. eds., Sampling for biological agents in the environment: Washington, D.C., ASM Press, p. 223-227 
Shaw, F. W., 1930, Culture medium for Bacterium tularense: Zentralblatt für Bakterilogie, Parasitenkunde und Infektionskrankheiten, v. 118, p. 216-217.

Santo Domingo, J.W., Siegring, S.C., and Haugland, R.A., 2003, Real-time PCR method to detect Enterococcus faecalis in water: Biotechnology Letters, v. 25, p. 261-265.

U.S. Environmental Protection Agency, 2001, Implementation and results of the Information Collection Rule supplemental surveys: Washington, D.C., EPA 815-R-01-003, 51 p.

U.S. Environmental Protection Agency, 2002, Method 1604Total Coliforms and Escherichia coli in water by membrane filtration using a simultaneous detection technique (MI medium): Washington, D.C., EPA 821-R-02-024, 18 p.

U.S. Environmental Protection Agency, 2005, Method 1623Cryptosporidium and Giardia in water by filtration/IMS/FA: Washington, D.C., EPA-815-R-05-002, 76 p.

Varma, M., Hester, J.D., Schaefer, F.W., III, Ware, M.W., and Lindquist, H.D.A., 2003, Detection of Cyclospora cayetanensis using a quantitative real-time PCR assay: Journal of Microbiological Methods, v. 53, p. 27-36.

Ware, M.W., Wymer, L., Lindquist, H.D.A., and Schaefer, F.W., III, 2003, Evaluation of an alternative IMS dissociation procedure for use with Method 1622-Detection of Cryptosporidium in water: Journal of Microbiological Methods, v. 55, p. 575-583.

Wilde, F.D., ed., 2005—present. Field measurements: U.S. Geological Survey Techniques of Water-Resources Investigations, book 9, chap. A6, Accessed September 10, 2007, at http://water.usgs.gov/owq/FieldManual/Chapter6/Ch6_contents.html

Wilson, I.G., 1997, Inhibition and facilitation of nucleic acid amplification: Applied and Environmental Microbiology, v. 63, p. 3741-3751.

Young, J.B., 1975, Epizontic of anthrax in Falls County, Texas: Journal of the American Veterinary Medical Association, v. 167, p. 842-843. 
